\title{
Efferocytosis in multisystem diseases (Review)
}

\author{
YIFAN ZHANG $^{1,2}$, YIRU WANG $^{1,2}$, JIE DING $^{1,2}$ and PING LIU ${ }^{1}$ \\ ${ }^{1}$ Longhua Hospital, Shanghai University of Traditional Chinese Medicine, Shanghai 200032; \\ ${ }^{2}$ Shanghai University of Traditional Chinese Medicine, Shanghai 201203, P.R. China
}

Received August 4, 2021; Accepted October 15, 2021

DOI: $10.3892 / \mathrm{mmr} .2021 .12529$

\begin{abstract}
Efferocytosis, the phagocytosis of apoptotic cells performed by both specialized phagocytes (such as macrophages) and non-specialized phagocytes (such as epithelial cells), is involved in tissue repair and homeostasis. Effective efferocytosis prevents secondary necrosis, terminates inflammatory responses, promotes self-tolerance and activates pro-resolving pathways to maintain homeostasis. When efferocytosis is impaired, apoptotic cells that could not be cleared in time aggregate, resulting in the necrosis of apoptotic cells and release of pro-inflammatory factors. In addition, defective efferocytosis inhibits the intracellular cholesterol reverse transportation pathways, which may lead to atherosclerosis,
\end{abstract}

Correspondence to: Professor Ping Liu, Longhua Hospital, Shanghai University of Traditional Chinese Medicine, 725 South Wan-Ping Road, Shanghai 200032, P.R. China

E-mail: liuping0207@126.com

Abbreviations: ACs, apoptotic cells; AD, Alzheimer's disease; AKT, protein kinase B; ALI, acute lung injury; AMPK, AMP-activated protein kinase; ARDS, acute respiratory distress syndrome; ATP, adenosine triphosphate; $A \beta$, amyloid $\beta$ protein; $\mathrm{CF}$, cystic fibrosis; COPD, chronic obstructive pulmonary disease; CX3CL1, CX3C chemokine ligand 1; CX3CR1, CX3C chemokine receptor 1; dsDNA, anti-double-stranded DNA; ERK5, extracellular signal-regulated kinase 5; GAS6, growth arrest specific protein 6; GXK, Guan Xinkang; HMGB1, high mobility group box-1; IBD, inflammatory bowel disease; LPC, lyso-phosphatidylcholine; LRP1, low-density lipoprotein receptor related proteins 1 ; LXR, liver X receptor; Mertk, Mer tyrosine protein kinase receptor; MFGE8, milk fat globule-epidermal growth factor 8; MI, myocardial infarction; NAFLD, non-alcoholic fatty liver disease; NASH, non-alcoholic steatohepatitis; NLRP3, NLR family, pyrin domain containing 3; PD, Parkinson's disease; PPAR, peroxisome proliferator receptor; ProS, Protein S; PtdSer, phosphatidylserine; RA, rheumatoid arthritis; ROS, reactive oxygen species; SCARF1, scavenger receptor class F member 1; SLE, systemic lupus erythematosus; SRB1, scavenger receptor 1; SS, Sjogren's syndrome; T1D, type 1 diabetes; TAM, TYRO3/Ax1/MER tyrosine kinase receptor; TIM, T-cell immunoglobulin and mucin domain-containing molecule

Key words: efferocytosis, cardiovascular diseases, respiratory diseases, liver and intestine diseases, autoimmune diseases, neurodegenerative diseases lung damage, non-alcoholic fatty liver disease and neurodegenerative diseases. The uncleared apoptotic cells can also release autoantigens, which can cause autoimmune diseases. Cancer cells escape from phagocytosis via efferocytosis. Therefore, new treatment strategies for diseases related to defective efferocytosis are proposed. This review illustrated the mechanisms of efferocytosis in multisystem diseases and organismal homeostasis and the pathophysiological consequences of defective efferocytosis. Several drugs and treatments available to enhance efferocytosis are also mentioned in the review, serving as new evidence for clinical application.

\section{Contents}

1. Introduction

2. Cardiovascular diseases

3. Respiratory diseases

4. Liver and intestine diseases

5. Autoimmune diseases

6. Neurodegenerative disorders

7. Tumor

8. Discussion

\section{Introduction}

Efferocytosis refers to the physiological process in which phagocytic cells clear apoptotic cells (ACs) (1). Phagocytosis involves both specialized phagocytes (such as macrophages) and non-specialized phagocytes (such as epithelial cells) (2).

Efferocytosis can be divided into four stages (2) (Fig. 1): i) 'Find me' stage. Chemotactic factors induce macrophages to recognize and surround ACs. The 'find me' signal molecules released by ACs are recognized by homologous receptors on the surface of phagocytes, to induce the migration and recruitment of phagocytes to ACs (3). ii) 'Eat me' stage. Phagocytic receptors of macrophages recognize and bind to the "eat me' signal molecules of ACs through bridging molecules. Following the programmed cell apoptosis, the 'eat me' signal molecule ligands on the AC surface are exposed, which can directly bind to the 'eat me' signal molecule receptors on the surface of phagocytes (4). Then, one end of the bridging molecules, as signal molecules related to efferocytosis, binds to the ligand of 'eat me' signal molecule of ACS and the other end binds to the receptor of the 'eat me' signal molecule on the 
surface of the phagocyte. Therefore, the phagocytes recognize and capture ACs in the direct 'ligand-receptor' binding form and the indirect 'ligand-bridging molecule-receptor' binding form (5). iii) Endocytosis stage. The 'eat me' signal molecules binding to phagocytic receptors activate the programmed cell removal system to form 'a phagocytic cup' and complete the endocytosis of ACs (6). iv) 'Post-phagocytosis' stage. Macrophages further digest and degrade apoptotic cell debris, activating multiple metabolic signaling pathways (7). After phagocytic cells engulf ACs, phagosomes are formed and then fuse with primary lysosomes to form phagolysosomes (8). When the phagolysosome matures, it begins to degrade ACs and release anti-inflammatory cytokines such as IL-10 and TGF- $\beta$ (5).

In efferocytosis, a number of molecules function to clear ACs promptly so that normal tissues cannot be damaged. First, the 'find me' signal molecules, consisting of direct ligand molecules and indirect signal molecules, are released after cell apoptosis. The direct ligand molecules include triphosphate nucleotides ATP, uridine-5'-triphosphate (9), lyso-phosphatidylcholine (10) and sphingosine-1-phosphate (11). The indirect signal molecules include CX3C chemokine ligand 1 (CX3CL1) protein (12). Second, the 'find me' signal is received by phagocytic cell receptors. Then the phagocytic receptors, including receptor $\mathrm{G} 2$ accumulation (13), CX3C chemokine receptor 1 (CX3CR1) (12), low-density lipoprotein receptor related proteins 1 (LRP1) (14) and scavenger receptor class B type 1 (SRB1), directly interact with 'eat-me' signal molecules on the surface of ACs, such as phosphatidylserine (PtdSer) (15), oxidized phospholipids and endoplasmic reticulum-resident protein calreticulin (16). The phagocytic receptors, such as Mer tyrosine protein kinase receptor (Mertk) (17), also interact with 'eat-me' signal molecules indirectly through bridging molecules (5). Extracellular bridging molecules link phagocytes with ACs, activate the phagocytic function of phagocytes and remove the ACs, such as milk fat globule-epidermal growth factor (MFGE8), serum complement C1q, transglutaminase 2, human growth arrest specific protein 6 (GAS6) and protein S (ProS) (17). These signaling molecules and extracellular bridging molecules are key to efferocytosis. In addition, the 'not eat me' signal in non-apoptotic cells prevents viable cells from being cleared by phagocytes. Among them, the best-known signal molecule is CD47 (18; Table I).

Efferocytosis is essential for human health, because it can prevent the deleterious effects of cell necrosis, thus maintaining the tissue and organ homeostasis (19) and the normal immune response (20). Apart from preventing secondary necrosis, efferocytosis has three functions: Terminating inflammatory responses, promoting self-tolerance and activating pro-resolving pathways (21). Efferocytosis triggers the production of anti-inflammatory and tissue-reparative cytokines, while defective efferocytosis may lead to hyperinflammation and diseases (5).

The present study summarized the current knowledge of efferocytosis and the links between efferocytosis and body homeostasis. Further, it reviewed the consequences of impaired efferocytosis in multisystem diseases (Fig. 2; Table II). Several drugs and treatments available to enhance efferocytosis are also mentioned to provide new evidence for clinical application.

\section{Cardiovascular diseases}

Studies on genome-wide association have discovered that common genetic variants in the chromosome 9p21 confer the risk of coronary artery disease, myocardial infarction (MI) (22) and ischemic stroke (23). The expression of calreticulin protein is reduced in the plaques of these allele carriers (24), while the area of the necrotic core and the number of ACs increase in the plaques of atherosclerosis (25). Calreticulin, located in the endoplasmic reticulum, serves a crucial role in cardiac embryogenesis. It affects cardiac development and myofibrillogenesis and is involved in the pathophysiology of several cardiac pathologies (26). Calreticulin binds to the 'eat me' ligand on the surface of ACs, activating LDLR4 on the surface of phagocytic cells and inducing phagocytosis (14). Therefore, the reduction of calreticulin protein of these allele carriers suppresses the 'eat me' signal and weakens the phagocytosis of ACs. This explains why efferocytosis is independent of traditional risk factors (such as hypertension, dyslipidemia, diabetes and smoking) of cardiovascular diseases (27).

Atherosclerosis, a major pathological basis for cardiovascular and cerebrovascular diseases, is also the key process in other diseases, such as chronic cerebral insufficiency and cerebral infarction. Atherosclerosis is considered to be a cholesterol storage disease and a lipid-driven inflammatory disease (28). Cholesterol loading is hypothesized to cause pro-inflammatory cytokine secretion and form intracellular cholesterol microcrystals that activate the inflammasome (29). In addition, cholesterol-laden macrophages are 'foam cells' that die easily and release their contents in advanced lesions and thereby can worsen the inflammatory status (30). As atherosclerosis is an inflammatory disease, various factors involved in the inflammatory response may be related to the formation of atherosclerotic plaques (31). TNF- $\alpha$ is elevated in the pro-inflammatory early-stage of atherosclerosis. TNF- $\alpha$ inhibits MFGE8, Mertk and LRP1 by activating the Toll-like receptor (TLR) (32) and upregulates CD47 expression to activate the 'not eat me' signal (33). TNF- $\alpha$ weakens the efferocytosis and prevents timely clearance of ACs, thereby aggravating the inflammatory response and further worsening atherosclerosis (34). The above reactions form a vicious circle. Therefore, the effect of efferocytosis is gradually impaired as the atherosclerotic plaque progresses.

In atherosclerosis, the clearance of ACs is essential to resolve inflammation. Efferocytosis promotes the resolution of inflammation in a stepwise manner. One step is to recognize and engulf ACs, which prevents AC accumulation and inflammatory agent secretion (35). The engulfment of ACs results in the acquisition of excess cellular materials such as lipids, carbohydrates, proteins and nucleic acids (36). Macrophages need to activate degradation and efflux pathways for increased metabolic load, which is crucial for inflammatory resolution and tissue repair (19). For instance, lipid metabolism activates the nuclear receptors peroxisome proliferator-activated receptor (PPAR) and liver $\mathrm{X}$ receptor (LXR)- $\alpha$, helping release anti-inflammatory cytokines, such as IL-10 and TGF- $\beta(37,38)$. Efferocytosis within the plaque is impaired when atherosclerotic plaque develops in the late stage (39). A study has confirmed that the ratio of apoptotic cell clearance is nineteen times higher in human tonsils as compared with 
A 'Find me' stage

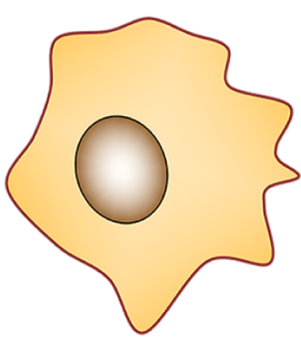

Phagocytes
'Find me' signal molecules release

Direct ligand molecules (ATP, UTP, S1P, LPC)

Indirect ligand molecules (CX3CL1)

Apoptotic cells
B 'Eat me' stage

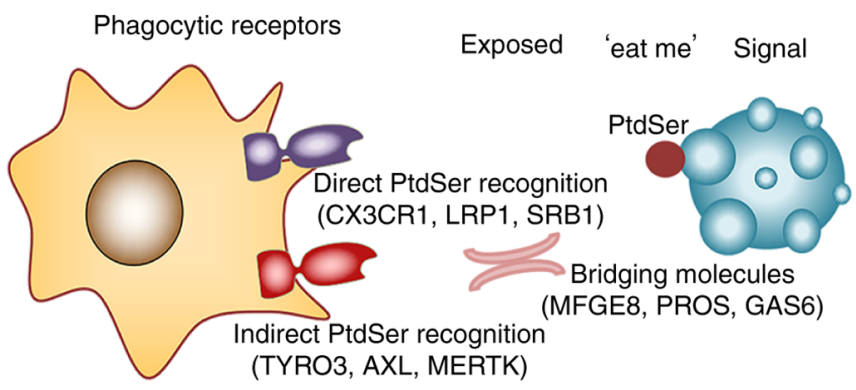

D 'Post-phagocytosis' stage

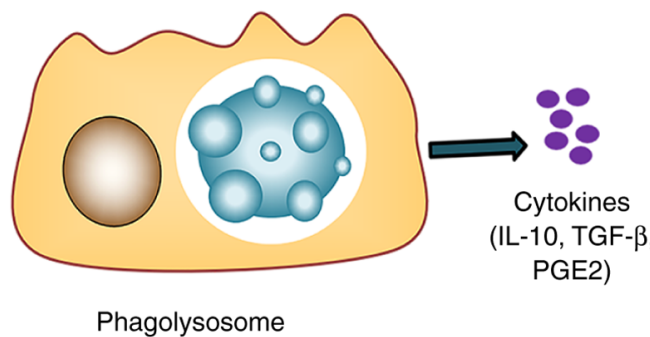

Figure 1. Four stages of efferocytosis. (A) 'Find me' stage. Chemotactic factors induce macrophages to recognize and surround ACs. The 'find me' signal molecules released by ACs are recognized by phagocytes, inducing the migration and recruitment of phagocytes to ACs. (B) 'Eat me' stage. Phagocytic receptors of macrophages recognize and bind to the 'eat me' signal molecules of ACs. (C) Endocytosis stage. Forming 'a phagocytic cup' completes the endocytosis of ACs. (D) 'Post-phagocytosis' stage. Macrophages further digest and degrade apoptotic cell debris, activating multiple metabolic signaling pathways. ATP, triphosphate nucleotides adenosine triphosphate; UTP, uridine-5'-triphosphate; S1P, sphingosine-1-phosphate; LPC, lyso-phosphatidylcholine; CX3CL1, CX3C chemokine ligand 1; CX3CR1, CX3C chemokine receptor 1; LRP1, low-density lipoprotein receptor related proteins 1; SRB1, scavenger receptor 1; MFGE8, milk fat globule-epidermal growth factor; ProS, protein S; PtdSer, phosphatidylserine; GAS6, growth arrest specific protein 6; TYRO3/AXL/MERTK, TAM receptors.

human atherosclerotic plaques (40). Schrijvers et al (40) found more apoptotic cells outside lesional phagocytes in advanced human coronary artery lesions. Defective efferocytosis leads to post-apoptotic cellular necrosis and the release of proinflammatory factors (41). Failed AC clearance, increased inflammation (42) and worsened atherosclerosis $(43,44)$ were found in mice lacking TIM-4, Mertk, MFGE8, or Pro S. As macrophage apoptosis accelerates under defective efferocytosis, the lipid-laden necrotic core enlarges with the progression of atherosclerotic plaques (45). Thinning fibrous cap, high-level inflammatory cytokines, apoptosis of intimal cells and expansion of the lipid-laden necrotic core all contribute to vulnerable plaques and acute coronary artery syndrome (46). The absence of efferocytosis signals also inhibits the subsequent intracellular cholesterol reverse transportation pathways (24), then promotes foam cell formation and initiates the development of atherosclerosis. C1q protects early atherosclerosis by promoting macrophage survival and improving the function of macrophage foam cells (47).

Effective efferocytosis can inhibit secondary cell necrosis and prevent dead cells from releasing inflammatory factors and toxic molecules, thereby slowing down atherosclerosis progression and reducing plaque vulnerability (32). Enhanced efferocytosis can reverse hypoxia in murine atherosclerosis to prevent necrotic core expansion (48). Natalicone ZB, the specific agonist of LXR, can facilitate efferocytosis, inhibit plaque formation and reduce the area of necrotic core (49). Conventional anti-atherosclerotic drugs, such as statins and non-steroidal PPAR $\gamma$ agonists, can enhance efferocytosis in plaques $(50,51)$. In atherosclerosis treatment, statin can reduce cholesterol and inflammation, repress the highly expressed Ras homologous gene family member $\mathrm{A}$, a negative regulator of phagocytosis in atherosclerotic lesions (50).

Experimental results have confirmed the regulatory role of extracellular signal-regulated kinase 5 (ERK5) in macrophage phagocytosis. ERK5, one of the mitogen-activated protein kinases, can maintain macrophage phagocytosis and prevent atherosclerosis progression (32). In LDLR ${ }^{-/}$mice, ERK5 gene knockout can aggravate atherosclerosis and inhibit the expression of efferocytosis-related proteins (52). ERK5 inhibitor can downregulate the phagocytosis of RAW264.7 cells in vitro (53). Thus, it can be concluded that regulating efferocytosis of macrophages through ERK5 can exert an anti-atherosclerosis effect.

Efferocytosis also serves a role in other cardiovascular diseases. In Wan et al (54), Mertk could clear apoptotic cardiomyocytes following MI, thus mitigating the progression to heart failure, while suppressed efferocytosis could increase infarct size, promote adverse ventricular remodeling and left ventricle functional deterioration after MI and ease the occurrence of cardiomyopathy.

These studies implicate that impaired efferocytosis can result in secondary necrosis, inflammation, cholesterol reverse disorder and thus lead to cardiovascular diseases, such as atherosclerosis and acute coronary artery syndrome. As a crucial modulator in cardiovascular diseases, efferocytosis is worthy of further investigation. 
Table I. Summary of efferocytosis related molecules.

\begin{tabular}{|c|c|c|c|c|}
\hline Author(s), year & Role in efferocytosis & Cell source & Molecules & (Refs.) \\
\hline Elliott et al, 2009 & 'Find me' signal & Apoptotic cells & ATP, UTP & (9) \\
\hline Lauber et al, 2003 & & & LPC & $(10)$ \\
\hline Gude et al, 2008 & & & S1P & (11) \\
\hline Truman et al, 2008 & & & CX3CL1 & (12) \\
\hline Peter et al, 2008 & & Phagocytic cells & G2A & (13) \\
\hline Truman et al, 2008 & & & CX3CR1 & (12) \\
\hline Gardai et al, 2005 & & & LRP1, & (14) \\
\hline Gardai et al, 2005 & & & SRB1 & (14) \\
\hline Elliott et al, 2009 & & & $\mathrm{P} 2 \mathrm{Y} 2$ & (9) \\
\hline Appelt et al, 2005 & 'Eat me' signal & Apoptotic cells & PtdSer & $(15)$ \\
\hline Nagata et al, 2010 & & & $\begin{array}{l}\text { oxidized phospholipids, endoplasmic } \\
\text { reticulum-resident protein calreticulin }\end{array}$ & $(16)$ \\
\hline Geng et al, 2017 & & Phagocytic cells & TAM, TIM, TG2 & (17) \\
\hline Geng et al, 2017 & Bridging molecules & $\begin{array}{l}\text { Apoptotic/ } \\
\text { phagocytic cell }\end{array}$ & $\begin{array}{l}\text { MFGE8, GAS6, Pro S, serum complement } \\
\text { C1q, Thbs1, Anx I }\end{array}$ & (17) \\
\hline Ravichandran, 2010 & 'Not eat me' signal & Apoptotic cells & $\mathrm{CD} 47, \mathrm{CD} 31$ & (18) \\
\hline Gheibi Hayat et al, 2019 & & Phagocytic cells & $\operatorname{SIRP} \alpha$ & (201) \\
\hline
\end{tabular}

Anx I, Annexin I; ATP, triphosphate nucleotides adenosine triphosphate; CX3CL1, CX3C chemokine ligand 1; CX3CR1, CX3C chemokine receptor 1; GAS6, human growth arrest specific protein 6; G2A, receptor G2 accumulation; LPC, lyso-phosphatidylcholine; LRP1, low-density lipoprotein receptor related proteins 1; MFGE8, milk fat globule-epidermal growth factor; PtdSer, phosphatidylserine; ProS, protein S; P2Y2, purnoreceptor-2; SIRP $\alpha$, signal regulatory protein alpha; SRB1, scavenger receptor 1; S1P, sphingosine-1-phosphate; TAM, TYRO3/Ax1/MER tyrosine kinase receptor; TG2, transglutaminase 2; TIM, T cell immunoglobulin mucin; Thbs 1, thrombospondin 1; UTP, uridine-5'-triphosphate.

\section{Respiratory diseases}

Lung diseases are closely related to efferocytosis due to the complex inflammatory and immune responses. When lung inflammation occurs, neutrophils are quickly recruited to the airways. Following phagocytosis of pathogens, neutrophils undergo apoptosis. This process is regulated by multiple genes and multiple factors, such as LPS, TNF- $\alpha$, Fas/Fas-L pathway, apoptotic genes, interleukins, interferons and Caspase protein (55). Phagocytosis clears apoptotic neutrophils to prevent the release of toxic substances and the subsequent damage to the surrounding tissues, thereby alleviating inflammation (55). Effective efferocytosis protects normal airways, alveolar structures and even the lung tissues (56). For example, Lee et al (57) found Mertk overexpression could attenuate bleomycin-induced lung injury in mice.

By contrast, due to impaired efferocytosis, the number of uncleared ACs increases, which prolongs inflammatory response in the mouse and human models of chronic obstructive pulmonary disease (COPD) and cystic fibrosis (CF) (58). COPD is characterized by chronic inflammation, extracellular matrix destruction and increased apoptosis of airway epithelial cells and neutrophils (59). The macrophage-mediated efferocytosis in the lungs of COPD patients weakens significantly, while efferocytosis strengthens in COPD patients who use statins (60).

Similarly, patients with CF or allergic asthma display protracted inflammation caused by defective efferocytosis $(61,62)$. CF is a heritable disease with infection, airway inflammation and bronchiectasis (63). Sputa examination has shown more ACs in CF patients compared with those with chronic bronchitis (64). Asthma is a complex syndrome with airflow obstruction, bronchial hyper-responsiveness and airway inflammation (65). The resolution of ovalbumin-induced allergic airway inflammation is delayed in Mer-deficient mice (66). Targeting T-cell immunoglobulin and mucin domain-containing molecule (TIM) 1 , a member of TIM receptor family, can modulate airway inflammation in mouse models of airway hyper-responsiveness (67). Grabiec et al (68) indicate that the deficiency of Axl receptor tyrosine kinase accelerates asthma progression by exaggerating airway inflammation. The prognosis of acute lung injury (ALI) in mouse models is also influenced by defective efferocytosis. MFGE8 deficient mice with lipopolysaccharide (LPS)-induced acute ALI showed increased inflammatory cytokines and decreased survival (69). Mertk can attenuate LPS-induced lung injury (70).

Common respiratory drugs, such as statins, macrolides and corticosteroids, can alleviate respiratory symptoms by enhancing efferocytosis. Macrolide antibiotics are reported to promote efferocytosis by upregulating the expression of bridging molecules such as collectins (71). These drugs have already been used to treat COPD, cystic fibrosis, or asthma (72). Mannose receptor may be a target of azithromycin to improve phagocytic ability (71). Azithromycin restores the phagocytic function of the airway macrophages by binding to PtdSer in COPD (73). Corticosteroids enhance efferocytosis by downregulating CD47-signal 
Table II. Summary of efferocytosis related molecules and multisystem diseases.

\begin{tabular}{|c|c|c|c|}
\hline Author(s), year & Diseases & Molecules & (Refs.) \\
\hline Fricker et al, 2012 & Alzheimer's disease & MFGE8 $\downarrow$ & $(146)$ \\
\hline Zheng et al, 2012 & & Tyro3 $\downarrow$ & $(145)$ \\
\hline Kojima et al, 2016 & Atherosclerosis & $\mathrm{CD} 47 \uparrow$ & $(33)$ \\
\hline Holden et al, 2019 & & GAS6 $\downarrow$ & $(202)$ \\
\hline Brophy et al, 2019 & & LRP1 $\downarrow$ & $(203)$ \\
\hline Ait-Oufella et al, 2008; Zhang et al, 2019; & & Mertk $\downarrow$ & $(204-206)$ \\
\hline \multicolumn{4}{|l|}{ Thorp et al, 2008} \\
\hline Ait-Oufella et al, 2007 & & MFGE8 $\downarrow$ & $(44)$ \\
\hline Boisvert et al, 2006 & & $\mathrm{TG} 2 \downarrow$ & $(207)$ \\
\hline Waterborg et al, 2018 & Arthritis & TAM receptors $\downarrow$ & $(122)$ \\
\hline Grabiec et al, 2017 & Asthma & Axl $\downarrow$ & $(68)$ \\
\hline Qi et al, 2013 & Autoimmune hepatitis & TAM receptors $\downarrow$ & $(111)$ \\
\hline Wan et al, 2013 & Cardiomyopathy & Mertk $\downarrow$ & $(54)$ \\
\hline Bosurgi et al, 2013 & Colon cancers & Axl $\downarrow$ & $(101)$ \\
\hline Akitake-Kawano et al, 2013 & & GAS6 $\downarrow$ & $(103)$ \\
\hline Bosurgi et al, 2013 & & Mertk $\downarrow$ & $(101)$ \\
\hline Llacuna et al, 2010 & Liver ischemia/reperfusion injury & GAS6 $\downarrow$ & $(95)$ \\
\hline Aziz et al, 2012 & Lung damage & MFGE8 $\downarrow$ & $(69)$ \\
\hline Gong et al, 2019 & Lupus nephritis & $\mathrm{AXL} \uparrow$ & $(208)$ \\
\hline Gong et al, 2019 & & GAS6 $\uparrow$ & $(208)$ \\
\hline Gong et al, 2019 & & Mertk $\uparrow$ & $(208)$ \\
\hline Tworkoski et al, 2013 & Melanoma & Mertk $\uparrow$ & $(209)$ \\
\hline Demarest et al, 2013 & & Tyro3 $\uparrow$ & $(210)$ \\
\hline Tutusaus et al, 2020 & Non-alcoholic steatohepatitis & Mertk $\downarrow$ & $(85)$ \\
\hline Xie et al, 2015 & Non-small cell lung cancer & Mertk $\uparrow$ & $(211)$ \\
\hline Lew et al, 2020 & Retinal degeneration & Mertk $\downarrow$ & $(177)$ \\
\hline Walport et al, 1998 & Systemic lupus erythematosus & $\mathrm{C} 1 \mathrm{q} \downarrow$ & $(212)$ \\
\hline Huang et al, 2017 & & MFGE8 $\uparrow$ & $(213)$ \\
\hline Zhu et al, 2014 & & Mertk $\uparrow$ & $(214)$ \\
\hline Bertolaccini et al, 2003 & & Pro $S \downarrow$ & $(215)$ \\
\hline Ramirez-Ortiz et al, 2013 & & SCARF1 $\downarrow$ & $(120)$ \\
\hline Xiao et al, 2012 & & TIM $1 \downarrow$ & (119) \\
\hline Chen et al, 2015 & Sjogren's syndrome & GAS6 $\downarrow$ & $(131)$ \\
\hline Qin et al, 2015 & & Axl $\downarrow$ & $(132)$ \\
\hline Qin et al, 2015 & & Tyro3 $\downarrow$ & $(132)$ \\
\hline Peng and Elkon, 2011 & Type 1 diabetes mellitus & MFGE8 $\downarrow$ & $(216)$ \\
\hline Avilla et al, 2011 & Thyroid cancer & Axl $\uparrow$ & $(217)$ \\
\hline Avilla et al, 2011 & & Tyro3 $\uparrow$ & $(217)$ \\
\hline Bossi et al, 2014 & Wound healing & $\mathrm{C} 1 \mathrm{q} \downarrow$ & $(180)$ \\
\hline
\end{tabular}

GAS6, growth arrest specific protein 6; LRP1, low-density lipoprotein receptor related proteins 1; MFGE8, milk fat globule-epidermal growth factor; SCARF1, scavenger receptor class F, member 1; TAM receptors, Tyro3/Ax1/Mertk; TG2, transglutaminase 2; TIM1, T-cell immunoglobulin and mucin domain-containing molecule 1.

regulatory protein (SIRP) and upregulating Mertk (74). Glucocorticoids, the most commonly used drugs for asthma and COPD, enhance macrophage phagocytosis in vitro and restore the efferocytosis of macrophages in the airway of patients with asthma by regulating Mertk and Pro S $(75,76)$. Grégoire et al (77) also found that blocking high mobility group box-1 (HMGB1) and activating AMP-activated protein kinase (AMPK) by metformin could enhance AC clearance and decrease lung inflammation in patients with acute respiratory distress syndrome (ARDS).

Several chronic lung diseases are characterized by an increased lung burden of uningested apoptotic cells and sustained lung inflammation (58). The efferocytic process favors tissue repair and inflammation suppression (78). Existing 


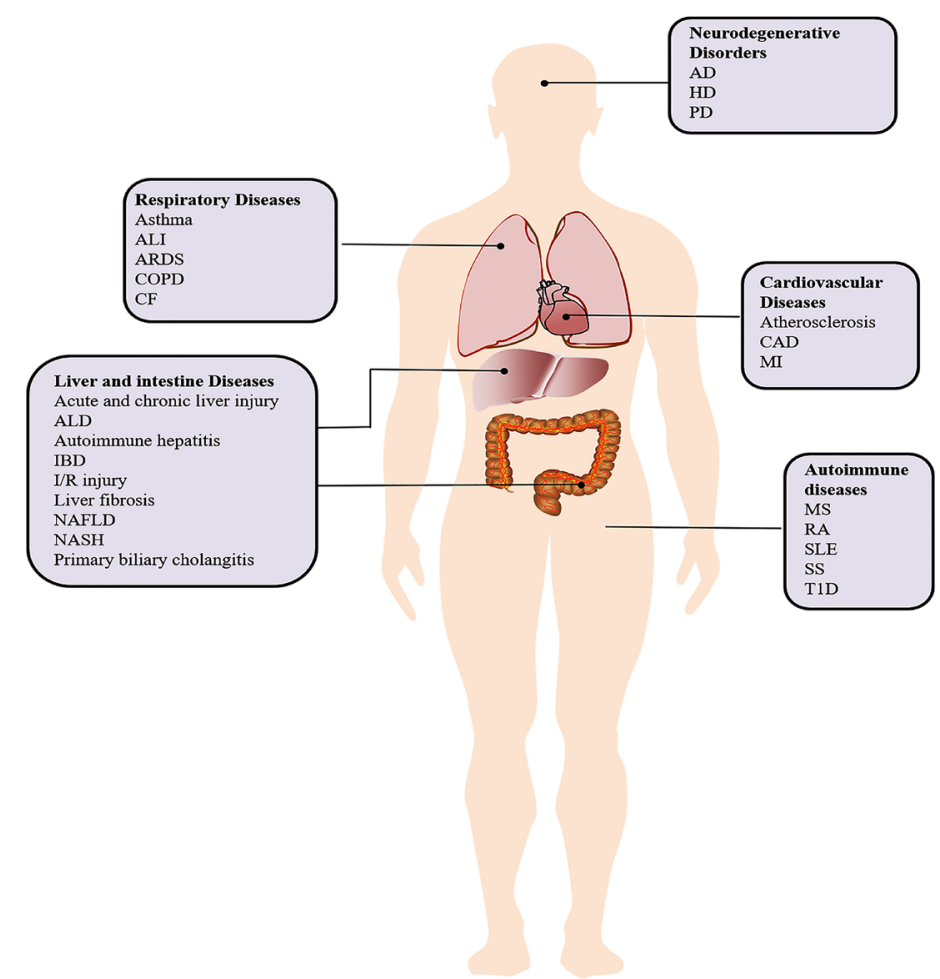

Figure 2. Efferocytosis in multisystem diseases. AD, Alzheimer's disease; ALD, alcoholic liver disease; ALI, acute lung injury; ARDS, acute respiratory distress syndrome; CAD, Coronary artery disease; $\mathrm{CF}$, cystic fibrosis; COPD, chronic obstructive pulmonary disease; HD, Huntington's disease; IBD, inflammatory bowel disease; I/R injury, ischemia-reperfusion injury; MI, Myocardial infarction; MS, multiple sclerosis; NAFLD, non-alcoholic fatty liver disease; NASH, non-alcoholic steatohepatitis; PD, Parkinson's disease; RA, rheumatoid arthritis; SLE, systemic lupus erythematosus; SS, Sjogren's syndrome; T1D, type 1 diabetes.

therapies such as corticosteroids, statins and macrolides may function in part by augmenting apoptotic cell clearance.

\section{Liver and intestine diseases}

Kupffer cells and other myeloid phagocytic cells, the most important hepatic efferocytes, are attracted into the liver to remove ACs after injury (79). Bukong et al (80) found that acute alcohol use could significantly impair the clearance of neutrophil extracellular traps by macrophages, which could contribute to prolonged liver inflammation and injury. Mediators released by neutrophils during NETosis can directly corrupt the recognition of apoptotic cells by phagocytes: HMGB1, for example, initiates pro-inflammatory signal whilst simultaneously preventing efferocytosis by obscuring PS recognition (81). In patients with alcoholic liver disease, alcohol and alcohol metabolites increase liver inflammation and steatosis (82). Wang et al (83) found alcohol inhibits MFGE8 gene expression and impairs efferocytosis and thus leading to hepatocyte necrosis, which explains why alcohol can cause liver damage from another perspective.

Defective efferocytosis also contributes to other liver diseases, such as fatty liver disease and primary biliary cholangitis (2). Following the phagocytosis of ACs, phagocytes increase cholesterol efflux activity to maintain lipid homeostasis. The engagement of PS receptors activates PPAR $\gamma / \delta$ and LXR, the regulators of cellular lipid homeostasis (37) and upregulates the phagocytic receptors, such as the TAM family, to accommodate to the increased cholesterol induced by phagocytosis $(36,84)$. Excessive accumulation of fatty acids caused by defective efferocytosis triggers oxidative stress and lipid peroxidation, leading to liver cell death/apoptosis, inflammation, liver steatosis and even lipotoxic liver cell damage. GAS6 and Mertk can protect cultured primary mouse hepatocytes against lipid toxicity via protein kinase B (AKT)/signal transducers and activators of transcription 3 (STAT3) signaling (85). The enhanced oxidative stress response and the reactive oxygen species (ROS) expression in fatty liver tissues exacerbate non-alcoholic fatty liver disease (NAFLD) (86). Mertk can protect primary macrophages from oxidative stress-induced apoptosis (87). The significantly upregulated NLR family, pyrin domain containing 3 (NLRP3) inflammasome aggravates NAFLD greatly (88). However, a study showed that TIM4 reduced the inflammation in NAFLD by suppressing NLRP3 inflammasome (89). High-level hepatocyte apoptosis is found in non-alcoholic steatohepatitis (NASH) patients (90). The delayed removal of apoptotic liver cells can cause liver damage, inflammation and fibrosis (91). Liver fibrosis, the pathological result of various chronic liver diseases, is associated with the dysregulation and polarization of M1/M2 macrophages (92). Efferocytosis can alleviate liver fibrosis by stimulating M2 macrophage polarization (93). Rantakari et al (94) clearly showed that the absence of stabilin-1 aggravates fibrosis in chronic liver injury following $\mathrm{CCl} 4$ administration.

TIM4 and GAS6 are critical proteins in the resolution of hepatic ischemia-reperfusion injury (95). The administration of recombinant GAS6 can protect GAS6-knockout mice from fulminant hepatic failure (96). GAS6 also protects primary mouse hepatocytes from hypoxia-induced cell death through AKT phosphorylation and diminishes inflammatory cytokines in vitro (95). In acute and chronic liver injury, the 
elevated Galectin-3 expression can facilitate phagocytosis via Mertk (97). Triantafyllou et al (98) demonstrate that Mertk ${ }^{+}$ macrophage, as a novel hepatoprotective target, can promote resolution responses and quell tissue-destructive responses following acute liver injury.

Phagocytic clearance of ACs also serves a role in intestinal inflammatory disorders. In the acute phase of murine experimental colitis, MFGE8 expression decreases in inflamed colons (99). However, recombinant MFGE8 ameliorates colitis by reducing inflammation and improving disease parameters, suggesting that it may be a useful therapeutic agent for colitis (99). A number of studies indicate that the receptor tyrosine kinases Axl and Mertk can promote the resolution of inflammation, serving as a potential therapeutic target for inflammatory bowel disease (IBD) (100-102). Compared with wild-type mice, $\mathrm{Axl}^{-/-} \mathrm{Mertk}^{-/}$mice and $\mathrm{GAS}^{-/-}$mice are more sensitive to dextran sulfate sodium, presenting with more severe colitis signs and more weight loss $(101,103)$.

Effective efferocytosis prevents apoptotic or necrotic cells from forming cell debris that can induce liver and intestine damage $(81,104)$. Efferocytosis serves a role in liver diseases by regulating lipid metabolism, inflammation and polarization (81). Also, since efferocytosis promotes the resolution of inflammation, it can be used to treat intestinal inflammatory disorders (104).

\section{Autoimmune diseases}

A large number of cells undergo apoptosis during the development and homeostasis of the body (105). There are two main pathways of apoptosis, extrinsic or death receptor pathway and intrinsic or mitochondrial pathway, which have been identified (106). Patients with autoimmune diseases show high levels of apoptotic cells, partly attributed to the massive apoptosis in phagocytes or in tissue cells, such as glomerular cell, epidermal keratinocytes and T cells (107). Efficient AC clearance maintains immune homeostasis by eliminating auto-antigens, as well as producing anti-inflammatory and immunosuppressive signals (3). By contrast, under defective efferocytosis, ACs cannot be removed in time (108). As a result, uncleared ACs may rupture and release harmful contents such as autoantigens, thus promoting immune response and resulting in autoimmune diseases, such as systemic lupus erythematosus (SLE), rheumatoid arthritis (RA), type 1 diabetes (T1D) and multiple sclerosis (MS) (109). Genetic evidence from mouse studies has demonstrated that failed or delayed efferocytosis might cause immune system disorders and the release of auto-antigens (110). TAM triple-knockout mice can develop autoimmune hepatitis at the age of six months, with rising transaminases and titers of autoantibodies to antinuclear antigen (111).

SLE damages multiple organs, such as the skin, joints, kidney, lungs, nervous system, heart and blood vessels (112). Autoantibodies against nuclear antigens, such as antinuclear antibodies and anti-double-stranded DNA (dsDNA), are found in SLE patients (113). Macrophages from SLE patients possess a weaker capability to engulf ACs (114). Defective clearance of ACs has been demonstrated to promote the autoantibody production in vivo (115). An analysis of 50 SLE patients indicates that GAS6/ProS-TAM system is associated with the disease activity of SLE in several ways (116). Several PS receptors and PS opsonins serve an essential role in efferocytosis, chronic inflammation and age-dependent autoimmunity. TAM triple (Mertk ${ }^{--}$, $\mathrm{Axl}^{-/-}$, Tyro3 ${ }^{-/}$) knockout mice develop a poly-autoimmune syndrome resembling SLE, with elevated titers of autoantibodies, uncontrolled B and T cell proliferation and lymphocyte accumulation (117). Similarly, TIM4-deficient mice, with hyperactivated $\mathrm{T}$ and $\mathrm{B}$ cells, develop autoantibodies to dsDNA, a specific antibody to SLE (118). Furthermore, knockouts of TIM-1 (119), scavenger receptor class F member 1 (SCARF1) (120) and CD300f (121) all share a common phenotype with SLE-like autoimmunity. These observations are evidenced by the defective AC clearance as an etiological cause of SLE.

The site of RA inflammation contains uncleared ACs, suggesting that RA is related to impaired efferocytosis. Waterborg et al (122) show that the deficiency of Axl and Mertk worsens arthritis in mice, whereas overexpressing their ligands ProS1 and GAS6 to activate these receptors can ameliorate arthritis. Other studies have demonstrated that activating LXR/PPAR $\gamma$ exerts therapeutic effects on the mouse model with inflammatory arthritis (123-125).

T1D is a T cell-mediated autoimmune disorder with insulin deficiency and hyperglycemia (126). Inefficient clearance of apoptotic pancreatic cells may aggravate inflammation and necrosis, thus accelerating the release of autoantigens (127). Defective wound healing is a characteristic of patients with T1D. Due to incomplete phagocytosis, dead cells accumulate at the wound site, which leads to inflammation and retard wound healing (128). Das et al (129) demonstrate that $\mathrm{MFGE}^{-/-}$mice develop systemic inflammation and MFGE8 exerts a potential therapeutic effect on diabetic wound.

Sjogren's syndrome (SS) is a chronic, progressive autoimmune disease, with dry mouth and eyes as the most frequent symptoms. The accumulation of ACs and a type I interferon signature have been observed in patients with SS and mouse models. The function of TAMs in efferocytosis and interferon response dampening is impaired in SS (130). Chen et al (131) found that decreased plasma GAS6 concentration is associated with SS and thus GAS6 may be a novel independent risk factor for SS. Similarly, another study shows that the level of Tyro3 and Axl was decreased in SS patients (132). These findings suggest that efferocytosis may be associated with disease activity or inflammation in SS.

Glucocorticoids, the most widely-used anti-inflammatory drugs, are used to treat SLE by promoting AC clearance and alleviating inflammation in an MFGE8-dependent way (133). Glucocorticoids can also upregulate Mer (134) and increase the expression of annexin A1 and lipoxin A receptors $(135,136)$. Long-term effects of glucocorticoids are reported to be dependent on PPAR $\gamma$ (137).

When efferocytosis fails, ACs can rupture and release cellular materials. Then the released cellular materials stimulate inflammatory and immunogenic reactions, which are likely to trigger an autoimmune response (138). Glucocorticoids treat autoimmune diseases by promoting efferocytosis, which provides more ideas for future treatment (139).

\section{Neurodegenerative disorders}

Phagocytosis in the brain is accomplished by microglia, a resident macrophage in the brain and spinal cord. The central 
nervous system also requires efficient efferocytosis to achieve homeostasis by clearing the dying cells and preventing the spillover of proinflammatory and neurotoxic molecules (140). Defective efferocytosis may lead to multiple neurodegenerative disorders, such as Alzheimer's disease (AD), Parkinson's disease (PD) and Huntington's disease. Excessive ACs have been detected in patients with neurodegenerative diseases (141). MFGE8, an endogenous protective factor, regulates microglial phagocytosis of apoptotic neurons and inhibits inflammation (142). In the central nervous system of mice, microglial cells lacking Mertk fail to clear ineffective synaptic connections, thus impairing hippocampal development and propagating neuronal damage (143).

$A D$ is characterized by the accumulation of hyperphosphorylated protein tau and amyloid $\beta$ (A $\beta)$ (144). Zheng et al (145) found that $\mathrm{A} \beta$ generation is significantly decreased by Tyro3 receptor overexpression in the cell model. A significant increase of amyloid plaques in the hippocampus and plaque-associated clusters of astroglia has been detected in a Tyro3 ${ }^{-/}$AD transgenic mouse model (145). Neuroinflammation serves a key role in AD development and progression. The expression of MFGE8, an anti-inflammatory agent, decreases in a mouse model of AD (146). Evidence suggests that MFGE8 can suppress A1 astrocytes and regulate microglia $\mathrm{M} 1 / \mathrm{M} 2$ alteration to prevent the death of neurons and oligodendrocytes by regulating $\mathrm{NF}-\kappa \mathrm{B}$ and PI3K-AKT $(147,148)$. Recombinant MFGE8 may have the potential to treat chronic inflammation in $\mathrm{AD}$, through inhibiting MAPK and NF- $\kappa$ B signaling pathways (149).

$\mathrm{PD}$ is a progressive neurological disorder characterized by $\alpha$-synuclein deposit (150). Dysregulated microglia phagocytosis has been recognized in PD and defective phagocytosis has also been observed in the monocytes of patients with PD (151). In PD models, CX3CR $1^{-/-}$mice show microglial neurotoxicity (152). Studies also reveal that microglia phagocytosed and cleared cellular debris of degenerating neurons through Clq-mediated pathway and scavenger receptors $(153,154)$. In the central nervous system, microglial phagocytic function is supported by bridging proteins (such as MFGE8 or Pro S) and TAM-receptor kinases (such as Axl and Mer) to clear PS-exposing neurons $(155,156)$. The study of Nakashima et al (157) suggests that MFGE8 may prevent $\mathrm{PD}$ by reversing the reduced mesencephalic dopamine neurons. Chronic neuroinflammation is also crucial in PD. Ghahremani et al (158) conclude that efferocytosis can change the macrophage phenotype into anti-inflammatory phenotype.

In conclusion, neuronal apoptotic debris is cleared by phagocytic cells through efferocytosis. Then the release of proinflammatory and antigenic autoimmune constituents is inhibited, which enhances the neuronal survival and axonal regeneration. The tremendous therapeutic potential of efferocytosis for neurodegenerative diseases requires further preclinical development.

\section{Tumors}

Efferocytosis also serves an essential role in tumors. Apoptotic cell clearance can have deleterious consequences within the tumor microenvironment, potentially affecting the natural progression of the disease and cancer treatments.
Efferocytosis can help generate a tumor-tolerant, immunosuppressive tumor micro-environment (159). In the tumor microenvironment, tumor-associated macrophages, which are largely polarized to the M2-like phenotype through PPAR- $\gamma$ and LXR- $\alpha$, exert pro-tumor effects by promoting angiogenesis, suppressing $\mathrm{T}$ cell infiltration and cytotoxic $\mathrm{T}$ cell function, remodeling extracellular matrix to promote invasion and metastasis of cancer cells and suppressing the immune system (160-162). Efferocytosis upregulates TAM receptor expression to promote macrophage polarization towards an immunosuppressive phenotype (163). Namely, the escape of malignant cells is supported by TAM-mediated efferocytosis, negative regulation of dendritic cell activity and dysregulated production of chemokines. MerTK overexpression has been found in a number of human cancers, including myeloid and lymphoblastic leukemia, melanoma and gliomas (164-166). Thus, TAM receptors on macrophages serve as exciting targets for cancer therapy by effecting macrophage phenotype and efferocytosis (167). A growing amount of evidence suggests that efferocytosis in the tumor microenvironment accelerates tumor progression, which provides new ideas for tumor treatment. For example, the blockade of PtdSer interacting with the efferocytosis of phagocytes sufficiently can inhibit tumor progression and metastasis (168). Studies demonstrate that Axl and Mer contribute to cell survival, migration, invasion, metastasis and chemosensitivity, which can be used as therapeutic targets (169-171).

Cancer cells have been found to escape from phagocytosis by upregulating 'don't eat me' molecules on their surface (172). Willingham et al (173) found that CD47 was highly expressed in ovarian, breast, colon, bladder, glioblastoma, hepatocellular carcinomas and prostate tumor cells; a high level of CD47 mRNA expression was associated with a decreased survival. Anti-CD47 antibodies can promote phagocytosis, inhibit tumor growth and prevent tumor metastasis. The anti-CD47 antibodies enhance cancer cell phagocytosis via inhibiting the SIRP $\alpha$ axis in anti-cancer therapy (174). These results suggest CD47 as a therapeutic target for solid tumors. Combing anti-CD47 antibodies and tumor-targeting therapies can achieve higher anti-cancer efficacies.

Other studies support that the enhanced efferocytosis can exert anti-tumor effects. A previous study has revealed that multiple myeloma is associated with reduced efferocytosis by monocytes (175). Some studies have demonstrated that the loss of Axl, Mertk and GAS6 can promote colon cancer $(101,103)$. Axl, Mertk and GAS6 can limit inflammation and reduce the risk of inflammation-associated colorectal cancer (176). The above evidence suggest the double edge sword role of efferocytosis in tumor. Therefore, the specific mechanism of efferocytosis in tumor requires further clarification.

\section{Discussion}

Efferocytosis can maintain homeostasis in biological evolution. Efferocytosis not only serves a role in the above-mentioned diseases, but also affects other diseases, such as skin diseases, retinal degeneration and wound healing. Loss of the phagocytosis receptor Mertk causes overt retinal degeneration (177). The protein CCN1 is a critical opsonin in skin injury by acting as a bridging molecule in neutrophil efferocytosis (178). 
Abnormal activation of complement-mediated phagocytosis also affects retinal diseases, such as glaucoma and age-related macular degeneration (179). C1q is found to stimulate endothelial cells proliferation and migration and to promote tube formation and sprouting of new vessels (180). C1q may represent a valuable therapeutic agent for wound healing. The critical role of efferocytosis in multisystem diseases provides new directions for the prevention and treatment of these diseases. More extensive and in-depth studies are needed to clarify the pathophysiological mechanism of efferocytosis in diseases.

Traditional Chinese medicine, which features multicomponents, multi-targets, multi-pathways and multi-effects, shows clear advantages in the treatment of diseases (181). Therefore, research on the role of traditional Chinese medicine in regulating efferocytosis promises a new direction of therapy development. More and more studies are being carried out on natural products for efferocytosis regulation.

Our previous studies (182-184) demonstrate the key role of efferocytosis in the development of atherosclerosis and the regulatory effect of efferocytosis on atherosclerosis. Guan Xin Kang (GXK), a formula designed by our research group and composed of Astragalus, Salvia, Leonurus, Trichosanthes kirilowii, Pinellia ternate and Scallions white, can improve the pathological changes in thoracic aorta, increase the phagocytosis rate of splenic macrophages and upregulate the protein expression of thrombospondin 1 (182) and TAM receptors (Tyro3/Axl/Mertk) in $\mathrm{LDLR}^{-/}$mouse (184). The expression of Mertk protein in RAW264.7 cells can be upregulated by sera medicated with GXK (183). The above results indicate that efferocytosis regulation may be effective in treating atherosclerosis. Treatment with catechins in rats can result in anti-atherogenic properties (185). Kaempferol, luteolin, ellagic acid and berberine can upregulate SR-BI expression and further inhibit ox-LDL uptake in macrophages (186-189). Caffeic acid and ferulic acid possess anti-atherogenic properties by enhancing HDL-mediated cholesterol efflux from the macrophages (190). These natural products, which have been proved to inhibit foam cell formation via efferocytosis (191), are potential drugs to improve cardiovascular diseases.

There are also several natural products that can regulate macrophage activation, recruitment and polarization to reduce inflammation, attenuate lipid accumulation and improve insulin sensitivity in NASH treatment, such as sparstolonin B (192), berberine (193) and celastrol (194). Baicalin promotes macrophage polarization to the M2-type in mice with IBD by enhancing the phagocytosis and efferocytosis of macrophages $(195,196)$. Polysaccharides from Ganoderma lucidum modulate microglial phagocytosis to attenuate neuroinflammation (197). An increasing number of natural products, such as pycnogenol (198), polysaccharides from the roots of Sanguisorba officinalis (199) and tea polysaccharides (200), enhance the phagocytic function of macrophages and could be used to treat diseases.

Having fewer adverse effects and multi-target properties, natural products are prospective medicinal components for the treatment of multi-system diseases in the future. Therefore, more research is needed to explore the mechanism of Chinese medicine that can regulate efferocytosis and provide reliable basis for disease treatment.

\section{Acknowledgements}

Not applicable.

\section{Funding}

The present review was supported by the Natural Science Foundation of China (grant nos. 81873117).

\section{Availability of data and materials}

Data sharing is not applicable to this article, as no data sets were generated or analyzed during the current study.

\section{Authors' contributions}

YZ conceptualized the review, performed the literature search and drafted the manuscript. YW and JD helped to draft and revise the manuscript. PL edited and revised the paper. All authors have read and approved the final version of the manuscript to be published.

\section{Ethics approval and consent to participate}

Not applicable.

\section{Patient consent for publication}

Not applicable.

\section{Competing interests}

The authors declare that they have no competing interests.

\section{References}

1. Thorp E and Tabas I: Mechanisms and consequences of efferocytosis in advanced atherosclerosis. J Leukoc Biol 86: 1089-1095, 2009.

2. Boada-Romero E, Martinez J, Heckmann BL and Green DR: The clearance of dead cells by efferocytosis. Nat Rev Mol Cell Biol 21: 398-414, 2020.

3. Trahtemberg U and Mevorach D: Apoptotic cells induced signaling for immune homeostasis in macrophages and dendritic cells. Front Immunol 8: 1356, 2017.

4. Segawa K and Nagata S: An apoptotic 'Eat Me' Signal: Phosphatidylserine exposure. Trends Cell Biol 25: 639-650, 2015.

5. Kourtzelis I, Hajishengallis G and Chavakis T: Phagocytosis of apoptotic cells in resolution of inflammation. Front Immunol 11: $553,2020$.

6. Freeman SA and Grinstein S: Phagocytosis: Receptors, signal integration and the cytoskeleton. Immunol Rev 262: 193-215, 2014.

7. Doran AC, Yurdagul A Jr and Tabas I: Efferocytosis in health and disease. Nat Rev Immunol 20: 254-267, 2020.

8. Levin R, Grinstein S and Canton J: The life cycle of phagosomes: Formation, maturation and resolution. Immunol Rev 273: 156-179, 2016.

9. Elliott MR, Chekeni FB, Trampont PC, Lazarowski ER, Kadl A, Walk SF, Park D, Woodson RI, Ostankovich M, Sharma P, et al: Nucleotides released by apoptotic cells act as a find-me signal to promote phagocytic clearance. Nature 461: 282-286, 2009.

10. Lauber K, Bohn E, Krober SM, Xiao YJ, Blumenthal SG, Lindemann RK, Marini P, Wiedig C, Zobywalski A, Baksh S, et al: Apoptotic cells induce migration of phagocytes via caspase-3-mediated release of a lipid attraction signal. Cell 113: 717-730, 2003. 
11. Gude DR, Alvarez SE, Paugh SW, Mitra P, Yu J, Griffiths R, Barbour SE, Milstien S and Spiegel S: Apoptosis induces expression of sphingosine kinase 1 to release sphingosine-1-phosphate as a 'come-and-get-me' signal. FASEB J 22: 2629-2638, 2008.

12. Truman LA, Ford CA, Pasikowska M, Pound JD, Wilkinson SJ, Dumitriu IE, Melville L, Melrose LA, Ogden CA, Nibbs R, et al: CX3CL1/fractalkine is released from apoptotic lymphocytes to stimulate macrophage chemotaxis. Blood 112: 5026-5036, 2008.

13. Peter C, Waibel M, Radu CG, Yang LV, Witte ON Schulze-Osthoff K, Wesselborg S and Lauber K: Migration to apoptotic 'find-me' signals is mediated via the phagocyte receptor G2A. J Biol Chem 283: 5296-5305, 2008.

14. Gardai SJ, McPhillips KA, Frasch SC, Janssen WJ, Starefeldt A, Murphy-Ullrich JE, Bratton DL, Oldenborg PA, Michalak M and Henson PM: Cell-surface calreticulin initiates clearance of viable or apoptotic cells through trans-activation of LRP on the phagocyte. Cell 123: 321-334, 2005.

15. Appelt U, Sheriff A, Gaipl US, Kalden JR, Voll RE and Herrmann M: Viable, apoptotic and necrotic monocytes expose phosphatidylserine: Cooperative binding of the ligand Annexin $\mathrm{V}$ to dying but not viable cells and implications for PS-dependent clearance. Cell Death Differ 12: 194-196, 2005.

16. Nagata S, Hanayama R and Kawane K: Autoimmunity and the clearance of dead cells. Cell 140: 619-630, 2010.

17. Geng K, Kumar S, Kimani SG, Kholodovych V, Kasikara C Mizuno K, Sandiford O, Rameshwar P, Kotenko SV and Birge RB: Requirement of gamma-carboxyglutamic acid modification and phosphatidylserine binding for the activation of Tyro3, Axl and Mertk receptors by growth arrest-specific 6 . Front Immunol 8: 1521, 2017.

18. Ravichandran KS: Find-me and eat-me signals in apoptotic cell clearance: Progress and conundrums. J Exp Med 207: 1807-1817, 2010 .

19. Tajbakhsh A, Rezaee M, Kovanen PT and Sahebkar A: Efferocytosis in atherosclerotic lesions: Malfunctioning regulatory pathways and control mechanisms. Pharmacol Ther 188: 12-25, 2018

20. Yoon KW: Dead cell phagocytosis and innate immune checkpoint. BMB Rep 50: 496-503, 2017.

21. Tajbakhsh A, Farahani N, Gheibihayat SM, Mirkhabbaz AM, Savardashtaki A, Hamblin MR and Mirzaei $H$ Autoantigen-specific immune tolerance in pathological and physiological cell death: Nanotechnology comes into view. Int Immunopharmacol 90: 107177, 2021.

22. Helgadottir A, Thorleifsson G, Manolescu A, Gretarsdottir S, Blondal T, Jonasdottir A, Jonasdottir A, Sigurdsson A, Baker A, Palsson A, et al: A common variant on chromosome 9p21 affects the risk of myocardial infarction. Science 316: 1491-1493, 2007.

23. Smith JG, Melander O, Lövkvist H, Hedblad B, Engström G, Nilsson P, Carlson J, Berglund G, Norrving B and Lindgren A: Common genetic variants on chromosome 9p21 confers risk of ischemic stroke: A large-scale genetic association study. Circ Cardiovasc Genet 2: 159-164, 2009.

24. Kojima Y, Downing K, Kundu R, Miller C, Dewey F, Lancero H, Raaz U, Perisic L, Hedin U, Schadt E, et al: Cyclin-dependent kinase inhibitor $2 \mathrm{~B}$ regulates efferocytosis and atherosclerosis. J Clin Invest 129: 2164, 2019.

25. Leeper NJ, Raiesdana A, Kojima Y, Kundu RK, Cheng H, Maegdefessel L, Toh R, Ahn GO, Ali ZA, Anderson DR, et al: Loss of CDKN2B promotes p53-dependent smooth muscle cell apoptosis and aneurysm formation. Arterioscler Thromb Vasc Biol 33: e1-e10, 2013

26. Martinho-Dias D, Leite-Moreira A and Castro-Chaves P: Calreticulin in the heart: From embryological development to cardiac pathology. Curr Mol Med 16: 12-22, 2016.

27. Cunnington MS and Keavney B: Genetic mechanisms mediating atherosclerosis susceptibility at the chromosome 9p21 locus. Curr Atheroscler Rep 13: 193-201, 2011.

28. Bäck M, Yurdagul A Jr, Tabas I, Öörni K and Kovanen PT: Inflammation and its resolution in atherosclerosis: mediators and therapeutic opportunities. Nat Rev Cardiol 6: 389-406, 2019

29. Duewell P, Kono H, Rayner KJ, Sirois CM, Vladimer G, Bauernfeind FG, Abela GS, Franchi L, Nuñez G, Schnurr M, et al NLRP3 inflammasomes are required for atherogenesis and activated by cholesterol crystals. Nature 464: 1357-1361, 2010.

30. Tabas I and Bornfeldt KE: Macrophage phenotype and function in different stages of atherosclerosis. Circ Res 118: 653-667, 2016

31. Ridker PM, Everett BM, Thuren T, MacFadyen JG, Chang WH, Ballantyne C, Fonseca F, Nicolau J, Koenig W, Anker SD, et al: Antiinflammatory therapy with canakinumab for atherosclerotic disease. N Engl J Med 377: 1119-1131, 2017.
32. Tabas I: Macrophage death and defective inflammation resolution in atherosclerosis. Nat Rev Immunol 10: 36-46, 2010.

33. Kojima Y, Volkmer JP, McKenna K, Civelek M, Lusis AJ, Miller CL, Direnzo D, Nanda V, Ye J, Connolly AJ, et al: CD47-blocking antibodies restore phagocytosis and prevent atherosclerosis. Nature 536: 86-90, 2016.

34. Martinet W, Schrijvers DM and De Meyer GR: Necrotic cell death in atherosclerosis. Basic Res Cardiol 106: 749-760, 2011.

35. Tabas I: 2016 Russell Ross memorial lecture in vascular biology: Molecular-cellular mechanisms in the progression of atherosclerosis. Arterioscler Thromb Vasc Biol 37: 183-189, 2017.

36. Han CZ and Ravichandran KS: Metabolic connections during apoptotic cell engulfment. Cell 147: 1442-1445, 2011

37. A-Gonzalez N, Bensinger SJ, Hong C, Beceiro S, Bradley MN, Zelcer N, Deniz J, Ramirez C, Díaz M, Gallardo G, et al: Apoptotic cells promote their own clearance and immune tolerance through activation of the nuclear receptor LXR. Immunity 31: 245-258, 2009.

38. Mukundan L, Odegaard JI, Morel CR, Heredia JE, Mwangi JW, Ricardo-Gonzalez RR, Goh YP, Eagle AR, Dunn SE, Awakuni JU, et al: PPAR-delta senses and orchestrates clearance of apoptotic cells to promote tolerance. Nat Med 15: 1266-1272, 2009.

39. Festuccia WT, Pouliot P, Bakan I, Sabatini DM and Laplante M: Myeloid-specific Rictor deletion induces M1 macrophage polarization and potentiates in vivo pro-inflammatory response to lipopolysaccharide. PLoS One 9: e95432, 2014.

40. Schrijvers DM, De Meyer GR, Kockx MM, Herman AG and Martinet W: Phagocytosis of apoptotic cells by macrophages is impaired in atherosclerosis. Arterioscler Thromb Vasc Biol 25: $1256-1261,2005$

41. Yurdagul A Jr, Subramanian M, Wang X, Crown SB, Ilkayeva OR, Darville L, Kolluru GK, Rymond CC, Gerlach BD, Zheng Z, et al: Macrophage metabolism of apoptotic cell-derived arginine promotes continual efferocytosis and resolution of injury. Cell Metab 31: 518-533.e10, 2020.

42. Kimani SG, Geng K, Kasikara C, Kumar S, Sriram G, Wu Y and Birge RB: Contribution of defective PS recognition and efferocytosis to chronic inflammation and autoimmunity. Front Immunol 5: 566, 2014

43. Cai B, Thorp EB, Doran AC, Sansbury BE, Daemen MJ, Dorweiler B, Spite M, Fredman G and Tabas I: MerTK receptor cleavage promotes plaque necrosis and defective resolution in atherosclerosis. J Clin Invest 127: 564-568, 2017.

44. Ait-Oufella H, Kinugawa K, Zoll J, Simon T, Boddaert J, Heeneman S, Blanc-Brude O, Barateau V, Potteaux S, Merval R, et al: Lactadherin deficiency leads to apoptotic cell accumulation and accelerated atherosclerosis in mice. Circulation 115: 2168-2177, 2007.

45. Schrijvers DM, De Meyer GR, Herman AG and Martinet W: Phagocytosis in atherosclerosis: Molecular mechanisms and implications for plaque progression and stability. Cardiovasc Res 73: 470-480, 2007.

46. Virmani R, Burke AP, Kolodgie FD and Farb A: Vulnerable plaque: The pathology of unstable coronary lesions. J Interv Cardiol 15: 439-446, 2002.

47. Pulanco MC, Cosman J, Ho MM, Huynh J, Fing K, Turcu J and Fraser DA: Complement protein Clq enhances macrophage foam cell survival and efferocytosis. J Immunol 198: 472-480, 2017.

48. Marsch E, Theelen TL, Demandt JA, Jeurissen M, van Gink M, Verjans R, Janssen A, Cleutjens JP, Meex SJ, Donners MM, et al: Reversal of hypoxia in murine atherosclerosis prevents necrotic core expansion by enhancing efferocytosis. Arterioscler Thromb Vasc Biol 34: 2545-2553, 2014.

49. Gui Y, Yao S, Yan H, Hu L, Yu C, Gao F, Xi C, Li H, Ye Y and Wang Y: A novel small molecule liver $X$ receptor transcriptional regulator, nagilactone $\mathrm{B}$, suppresses atherosclerosis in apoE-deficient mice. Cardiovasc Res 112: 502-514, 2016.

50. Salman H, Bergman M, Djaldetti M and Bessler H: Hydrophobic but not hydrophilic statins enhance phagocytosis and decrease apoptosis of human peripheral blood cells in vitro. Biomed Pharmacother 62: 41-45, 2008.

51. Ivanova EA, Myasoedova VA, Melnichenko AA and Orekhov AN: Peroxisome proliferator-activated receptor (PPAR) gamma agonists as therapeutic agents for cardiovascular disorders: Focus on atherosclerosis. Curr Pharm Des 23: 1119-1124, 2017.

52. Heo KS, Cushman HJ, Akaike M, Woo CH, Wang X, Qiu X, Fujiwara K and Abe J: ERK 5 activation in macrophages promotes efferocytosis and inhibits atherosclerosis. Circulation 130: 180-191, 2014 
53. Wang $\mathrm{J}$ and Liu P: Effects of ERK5 inhibitors on macrophages efferocytosis and the expression of ProS and Axl. Journal of Jinan University (Natural Science \& Medicine Edition) 39: 93-98, 2018 (In Chinese).

54. Wan E, Yeap XY, Dehn S, Terry R, Novak M, Zhang S, Iwata S, Han X, Homma S, Drosatos K, et al: Enhanced efferocytosis of apoptotic cardiomyocytes through myeloid-epithelial-reproductive tyrosine kinase links acute inflammation resolution to cardiac repair after infarction. Circ Res 113: 1004-1012, 2013.

55. Fox S, Leitch AE, Duffin R, Haslett C and Rossi AG: Neutrophil apoptosis: Relevance to the innate immune response and inflammatory disease. J Innate Immun 2: 216-227, 2010.

56. Hodge S, Tran HB, Hamon R, Roscioli E, Hodge G, Jersmann H, Ween M, Reynolds PN, Yeung A, Treiberg J and Wilbert S: Nonantibiotic macrolides restore airway macrophage phagocytic function with potential anti-inflammatory effects in chronic lung diseases. Am J Physiol Lung Cell Mol Physiol 312: L678-L1687, 2017.

57. Lee YJ, Lee SH, Youn YS, Choi JY, Song KS, Cho MS and Kang JL: Preventing cleavage of Mer promotes efferocytosis and suppresses acute lung injury in bleomycin treated mice. Toxicol Appl Pharmacol 263: 61-72, 2012.

58. McCubbrey AL and Curtis JL: Efferocytosis and lung disease. Chest 143: 1750-1757, 2013

59. Lareau SC, Fahy B, Meek P and Wang A: Chronic obstructive pulmonary disease (COPD). Am J Respir Crit Care Med 199: P1-P2, 2019.

60. Noda N, Matsumoto K, Fukuyama S, Asai Y, Kitajima H, Seki N, Matsunaga Y, Kan-O K, Moriwaki A, Morimoto K, et al: Cigarette smoke impairs phagocytosis of apoptotic neutrophils by alveolar macrophages via inhibition of the histone deacetylase/Rac/CD9 pathways. Int Immunol 25: 643-650, 2013.

61. Krysko O, Vandenabeele P, Krysko DV and Bachert C: Impairment of phagocytosis of apoptotic cells and its role in chronic airway diseases. Apoptosis 15: 1137-1146, 2010

62. Simpson JL, Gibson PG, Yang IA, Upham J, James A, Reynolds PN and Hodge S; AMAZES Study Research Group: Impaired macrophage phagocytosis in non-eosinophilic asthma. Clin Exp Allergy 43: 29-35, 2013.

63. Stanton BF: Cystic fibrosis. Pediatr Clin North Am 63: xv, 2016.

64. Vandivier RW, Fadok VA, Ogden CA, Hoffmann PR, Brain JD, Accurso FJ, Fisher JH, Greene KE and Henson PM: Impaired clearance of apoptotic cells from cystic fibrosis airways. Chest 121 (Suppl 3): S89, 2002.

65. Mishra V, Banga J and Silveyra P: Oxidative stress and cellular pathways of asthma and inflammation: Therapeutic strategies and pharmacological targets. Pharmacol Ther 181: 169-182, 2018

66. Felton JM, Lucas CD Dorward DA, Duffin R, Kipari T, Vermeren S, Robb CT, MacLeod KG, Serrels B, Schwarze J, et al: Mer-mediated eosinophil efferocytosis regulates resolution of allergic airway inflammation. J Allergy Clin Immunol 142: 1884-1893.e6, 2018.

67. Freeman GJ, Casasnovas JM, Umetsu DT and DeKruyff RH: TIM genes: A family of cell surface phosphatidylserine receptors that regulate innate and adaptive immunity. Immunol Rev 235: $172-189,2010$.

68. Grabiec AM, Denny N, Doherty JA, Happonen KE, Hankinson J, Connolly E, Fife ME, Fujimori T, Fujino N, Goenka A, et al: Diminished airway macrophage expression of the Axl receptor tyrosine kinase is associated with defective efferocytosis in asthma. J Allergy Clin Immunol 140 1144-1146.e4, 2017

69. Aziz M, Matsuda A, Yang WL, Jacob A and Wang P: Milk fat globule-epidermal growth factor-factor 8 attenuates neutrophil infiltration in acute lung injury via modulation of CXCR2 J Immunol 189: 393-402, 2012

70. Choi JY, Park HJ, Lee YJ, Byun J, Youn YS, Choi JH, Woo SY and Kang JL: Upregulation of Mer receptor tyrosine kinase signaling attenuated lipopolysaccharide-induced lung inflammation. J Pharmacol Exp Ther 344: 447-458, 2013.

71. Hodge S, Hodge G, Jersmann H, Matthews G, Ahern J, Holmes M and Reynolds PN: Azithromycin improves macrophage phagocytic function and expression of mannose receptor in chronic obstructive pulmonary disease. Am J Respir Crit Care Med 178: $139-148,2008$

72. Yamaryo T, Oishi K, Yoshimine H, Tsuchihashi Y, Matsushima K and Nagatake T: Fourteen-member macrolides promote the phosphatidylserine receptor-dependent phagocytosis of apoptotic neutrophils by alveolar macrophages. Antimicrob Agents Chemother 47: 48-53, 2003
73. Hodge S, Hodge G, Brozyna S, Jersmann H, Holmes M and Reynolds PN: Azithromycin increases phagocytosis of apoptotic bronchial epithelial cells by alveolar macrophages. Eur Respir J 28: 486-495, 2006.

74. Xiong Z, Leme AS, Ray P, Shapiro SD and Lee JS: CX3CR1+ lung mononuclear phagocytes spatially confined to the interstitium produce TNF- $\alpha$ and IL- 6 and promote cigarette smoke-induced emphysema. J Immunol 186: 3206-3214, 2011.

75. McColl A, Bournazos S, Franz S, Perretti M, Morgan BP, Haslett C and Dransfield I: Glucocorticoids induce protein S-dependent phagocytosis of apoptotic neutrophils by human macrophages. J Immunol 183: 2167-2175, 2009.

76. Zizzo G, Hilliard BA, Monestier M and Cohen PL: Efficient clearance of early apoptotic cells by human macrophages requires M2c polarization and MerTK induction. J Immunol 189: 3508-3520, 2012.

77. Grégoire M, Uhel F, Lesouhaitier M, Gacouin A, Guirriec M, Mourcin F, Dumontet E, Chalin A, Samson M, Berthelot LL, et al: Impaired efferocytosis and neutrophil extracellular trap clearance by macrophages in ARDS. Eur Respir J 52: 1702590, 2018.

78. Grabiec AM and Hussell T: The role of airway macrophages in apoptotic cell clearance following acute and chronic lung inflammation. Semin Immunopathol 38: 409-423, 2016.

79. Krenkel $\mathrm{O}$ and Tacke F: Liver macrophages in tissue homeostasis and disease. Nat Rev Immunol 17: 306-321, 2017.

80. Bukong TN, Cho Y, Iracheta-Vellve A, Saha B, Lowe P, Adejumo A, Furi I, Ambade A, Gyongyosi B, Catalano D, et al: Abnormal neutrophil traps and impaired efferocytosis contribute to liver injury and sepsis severity after binge alcohol use. J Hepatol 69: 1145-1154, 2018.

81. Horst AK, Tiegs G and Diehl L: Contribution of macrophage efferocy tosis to liver homeostasis and disease. Front Immunol 10: 2670, 2019.

82. Rocco A, Compare D, Angrisani D, Sanduzzi Zamparelli M and Nardone G: Alcoholic disease: Liver and beyond. World J Gastroenterol 20: 14652-14659, 2014

83. Wang X, Bu HF, Zhong W, Asai A, Zhou Z and Tan XD: MFG-E8 and HMGB1 are involved in the mechanism underlying alcohol-induced impairment of macrophage efferocytosis. Mol Med 19: 170-182, 2013.

84. Roszer T, Menendez-Gutierrez MP, Lefterova MI, Alameda D, Núñez V, Lazar MA, Fischer T and Ricote M: Autoimmune kidney disease and impaired engulfment of apoptotic cells in mice with macrophage peroxisome proliferator-activated receptor gamma or retinoid X receptor alpha deficiency. J Immunol 186: 621-631, 2011.

85. Tutusaus A, de Gregorio E, Cucarull B, Cristóbal H, Aresté C, Graupera I, Coll M, Colell A, Gausdal G, Lorens JB, et al: A functional role of GAS6/TAM in nonalcoholic steatohepatitis progression implicates AXL as therapeutic target. Cell Mol Gastroenterol Hepatol 9: 349-368, 2020.

86. Ashraf NU and Sheikh TA: Endoplasmic reticulum stress and Oxidative stress in the pathogenesis of Non-alcoholic fatty liver disease. Free Radic Res 49: 1405-1418, 2015.

87. Anwar A, Keating AK, Joung D, Sather S, Kim GK, Sawczyn KK, Brandão L, Henson PM and Graham DK: Mer tyrosine kinase (MerTK) promotes macrophage survival following exposure to oxidative stress. J Leukoc Biol 86: 73-79, 2009.

88. Mridha AR, Wree A, Robertson AAB, Yeh MM, Johnson CD, Van Rooyen DM, Haczeyni F, Teoh NC, Savard C, Ioannou GN, et al: NLRP3 inflammasome blockade reduces liver inflammation and fibrosis in experimental NASH in mice. J Hepatol 66: 1037-1046, 2017.

89. Liu W, Bai F, Wang H, Liang Y, Du X, Liu C, Cai D, Peng J, Zhong G, Liang X, et al: Tim-4 inhibits NLRP3 inflammasome via the LKB1/AMPK $\alpha$ pathway in macrophages. J Immunol 203: 990-1000, 2019.

90. El Bassat H, Ziada DH, Hasby EA, Nagy H and Abo Ryia MH: Apoptotic and anti-apoptotic seromarkers for assessment of disease severity of non-alcoholic steatohepatitis. Arab J Gastroenterol 15: 6-11, 2014.

91. de Alwis NM and Day CP: Non-alcoholic fatty liver disease: The mist gradually clears. J Hepatol 48 (Suppl 1): S104-S112, 2008.

92. Yao Q, Li S, Li X, Wang F and Tu C: Myricetin modulates macrophage polarization and mitigates liver inflammation and fibrosis in a murine model of nonalcoholic steatohepatitis. Front Med (Lausanne) 7: 71, 2020.

93. Yang M, Liu J, Piao C, Shao J and Du J: ICAM-1 suppresses tumor metastasis by inhibiting macrophage M2 polarization through blockade of efferocytosis. Cell Death Dis 6: e1780, 2015. 
94. Rantakari P, Patten DA, Valtonen J, Karikoski M, Gerke H, Dawes H, Laurila J, Ohlmeier S, Elima K, Hübscher SG, et al: Stabilin-1 expression defines a subset of macrophages that mediate tissue homeostasis and prevent fibrosis in chronic liver injury. Proc Natl Acad Sci USA 113: 9298-9303, 2016.

95. Llacuna L, Bárcena C, Bellido-Martín L, Fernández L, Stefanovic M, Marí M, García-Ruiz C, Fernández-Checa JC, García de Frutos $\mathrm{P}$ and Morales A: Growth arrest-specific protein 6 is hepatoprotective against murine ischemia/reperfusion injury. Hepatology 52: 1371-1379, 2010.

96. Lafdil F, Chobert MN, Deveaux V, Zafrani ES, Mavier P, Nakano T, Laperche Y and Brouillet A: Growth arrest-specific protein 6 deficiency impairs liver tissue repair after acute toxic hepatitis in mice. J Hepatol 51: 55-66, 2009.

97. Caberoy NB, Alvarado G, Bigcas JL and Li W: Galectin-3 is a new MerTK-specific eat-me signal. J Cell Physiol 227: 401-407, 2012.

98. Triantafyllou E, Pop OT, Possamai LA, Wilhelm A, Liaskou E Singanayagam A, Bernsmeier C, Khamri W, Petts G, Dargue R, et al: MerTK expressing hepatic macrophages promote the resolution of inflammation in acute liver failure. Gut 67: 333-347, 2018.

99. Otani A, Ishihara S, Aziz MM, Oshima N, Mishima Y, Moriyama I, Yuki T, Amano Y, Ansary MM and Kinoshita Y: Intrarectal administration of milk fat globule epidermal growth factor-8 protein ameliorates murine experimental colitis. Int J Mol Med 29: 349-356, 2012

100. Rothlin CV, Leighton JA and Ghosh S: Tyro3, Axl and Mertk receptor signaling in inflammatory bowel disease and colitis-associated cancer. Inflamm Bowel Dis 20: 1472-1480, 2014

101. Bosurgi L, Bernink JH, Delgado Cuevas V, Gagliani N, Joannas L, Schmid ET, Booth CJ, Ghosh S and Rothlin CV: Paradoxical role of the proto-oncogene Axl and Mer receptor tyrosine kinases in colon cancer. Proc Natl Acad Sci USA 110 13091-13096, 2013.

102. Steiner CA, Rodansky ES, Johnson LA, Berinstein JA, Cushing KC, Huang S, Spence JR and Higgins PDR: AXL is a potential target for the treatment of intestinal fibrosis. Inflamm Bowel Dis 27: 303-316, 2021.

103. Akitake-Kawano R, Seno H, Nakatsuji M, Kimura Y, Nakanishi Y, Yoshioka T, Kanda K, Kawada M, Kawada K, Sakai Y and Chiba T: Inhibitory role of Gas6 in intestinal tumorigenesis. Carcinogenesis 34: 1567-1574, 2013.

104. Shankman LS, Fleury ST, Evans WB, Penberthy KK, Arandjelovic S, Blumberg RS, Agaisse $\mathrm{H}$ and Ravichandran KS: Efferocytosis by Paneth cells within the intestine. Curr Biol 31: 2469-2476.e5, 2021

105. Fuchs Y and Steller H: Programmed cell death in animal development and disease. Cell 147: 742-758, 2011

106. Biermann M, Maueröder C, Brauner JM, Chaurio R, Janko C, Herrmann $M$ and Muñoz LE: Surface code-biophysical signals for apoptotic cell clearance. Phys Biol 10: 065007, 2013.

107. Yang F, He Y, Zhai Z and Sun E: Programmed cell death pathways in the pathogenesis of systemic lupus erythematosus. J Immunol Res 2019: 3638562, 2019.

108. Tajbakhsh A, Rezaee M, Barreto GE, Moallem SA, Henney NC and Sahebkar A: The role of nuclear factors as 'Find-Me'/alarmin signals and immunostimulation in defective efferocytosis and related disorders. Int Immunopharmacol 80: 106134,2020

109. Silva MT, do Vale A and dos Santos NM: Secondary necrosis in multicellular animals: An outcome of apoptosis with pathogenic implications. Apoptosis 13: 463-482, 2008.

110. Muñoz LE, Lauber K, Schiller M, Manfredi AA and Herrmann M: The role of defective clearance of apoptotic cells in systemic autoimmunity. Nat Rev Rheumatol 6: 280-289, 2010.

111. Qi N, Liu P, Zhang Y, Wu H, Chen Y and Han D: Development of a spontaneous liver disease resembling autoimmune hepatitis in mice lacking tyro3, axl and mer receptor tyrosine kinases PLoS One 8: e66604, 2013.

112. Mills JA: Systemic lupus erythematosus. N Engl J Med 330 1871-1879, 1994.

113. Yaniv G, Twig G, Shor DB, Furer A, Sherer Y, Mozes O, Komisar O, Slonimsky E, Klang E, Lotan E, et al: A volcanic explosion of autoantibodies in systemic lupus erythematosus: A diversity of 180 different antibodies found in SLE patients. Autoimmun Rev 14: 75-79, 2015.
114. Huang WN, Tso TK, Wu HC, Yang HF and Tsay GJ: Impaired phagocytosis of apoptotic cell material in serologically active clinically quiescent patients with systemic lupus erythematosis. Int J Rheum Dis 19: 1310-1316, 2016.

115. Sakamoto K, Fukushima Y, Ito K, Matsuda M, Nagata S, Minato N and Hattori M: Osteopontin in Spontaneous Germinal Centers inhibits apoptotic cell engulfment and promotes Anti-Nuclear antibody production in Lupus-Prone Mice. J Immunol 197: 2177-2186, 2016.

116. Recarte-Pelz P, Tàssies D, Espinosa G, Hurtado B, Sala N, Cervera R, Reverter JC and de Frutos PG: Vitamin K-dependent proteins GAS6 and Protein S and TAM receptors in patients of systemic lupus erythematosus: Correlation with common genetic variants and disease activity. Arthritis Res Ther 15: R41, 2013.

117. Lu Q and Lemke G: Homeostatic regulation of the immune system by receptor tyrosine kinases of the Tyro 3 family. Science 293: 306-311, 2001.

118. Rodriguez-Manzanet R, Sanjuan MA, Wu HY, Quintana FJ, Xiao S, Anderson AC, Weiner HL, Green DR and Kuchroo VK $\mathrm{T}$ and $\mathrm{B}$ cell hyperactivity and autoimmunity associated with niche-specific defects in apoptotic body clearance in TIM-4-deficient mice. Proc Natl Acad Sci USA 107: 8706-8711, 2010.

119. Xiao S, Brooks CR, Zhu C, Wu C, Sweere JM, Petecka S, Yeste A, Quintana FJ, Ichimura T, Sobel RA, et al: Defect in regulatory B-cell function and development of systemic autoimmunity in T-cell Ig mucin 1 (Tim-1) mucin domain-mutant mice. Proc Natl Acad Sci USA 109: 12105-12110, 2012.

120. Ramirez-Ortiz ZG, Pendergraft WF III, Prasad A, Byrne MH, Iram T, Blanchette CJ, Luster AD, Hacohen N, El Khoury J and Means TK: The scavenger receptor SCARF1 mediates the clearance of apoptotic cells and prevents autoimmunity. Nat Immunol 14: 917-926, 2013.

121. Tian L, Choi SC, Murakami Y, Allen J, Morse HC III, Qi CF, Krzewski K and Coligan JE: p85 $\alpha$ recruitment by the CD300f phosphatidylserine receptor mediates apoptotic cell clearance required for autoimmunity suppression. Nat Commun 5: 3146, 2014

122. Waterborg CEJ, Koenders MI, van Lent PLEM, van der Kraan PM and van de Loo FAJ: Tyro3/Axl/Mertk-deficient mice develop bone marrow edema which is an early pathological marker in rheumatoid arthritis. PLoS One 13: e0205902, 2018.

123. Park MC, Kwon YJ, Chung SJ, Park YB and Lee SK: Liver X receptor agonist prevents the evolution of collagen-induced arthritis in mice. Rheumatology (Oxford) 49: 882-890, 2010

124. Huang Y, Fu X, Lyu X, Xu Z, He Z, Zhang Y, Zeng Y, He F and Huang G: Activation of LXR attenuates collagen-induced arthritis via suppressing BLyS production. Clin Immunol 161: 339-347, 2015.

125. Zhu X, Chen F, Lu K, Wei A, Jiang Q and Cao W: PPAR $\gamma$ preservation via promoter demethylation alleviates osteoarthritis in mice. Ann Rheum Dis 78: 1420-1429, 2019.

126. Noble JA: Immunogenetics of type 1 diabetes: A comprehensive review. J Autoimmun 64: 101-112, 2015.

127. Rodriguez-Fernandez S, Pujol-Autonell I, Brianso F, Perna-Barrull D, Cano-Sarabia M, Garcia-Jimeno S, Villalba A, Sanchez A, Aguilera E, Vazquez F, et al: Phosphatidylserine-liposomes promote tolerogenic features on dendritic cells in human type 1 diabetes by apoptotic mimicry. Front Immunol 9: 253, 2018.

128. Khanna S, Biswas S, Shang Y, Collard E, Azad A, Kauh C, Bhasker V, Gordillo GM, Sen CK and Roy S: Macrophage dysfunction impairs resolution of inflammation in the wounds of diabetic mice. PLoS One 5: e9539, 2010

129. Das A, Ghatak S, Sinha M, Chaffee S, Ahmed NS, Parinandi NL, Wohleb ES, Sheridan JF, Sen CK and Roy S: Correction of MFG-E8 resolves inflammation and promotes cutaneous wound healing in diabetes. J Immunol 196: 5089-5100, 2016.

130. Witas R, Peck AB, Ambrus JL and Nguyen CQ: Sjogren's syndrome and TAM receptors: A possible contribution to disease onset. J Immunol Res 2019: 4813795, 2019.

131. Chen CH, Chen HC, Chang CC, Peng YJ, Lee CH, Shieh YS, Hung YJ and Lin YF: Growth arrest-specific 6 protein in patients with Sjögren syndrome: Determination of the plasma level and expression in the labial salivary gland. PLoS One 10: e0139955, 2015.

132. Qin B, Wang J, Ma N, Yang M, Fu H, Liang Y, Huang F, Yang Z and Zhong R: The association of Tyro3/Axl/Mer signaling with inflammatory response, disease activity in patients with primary Sjögren's syndrome. Joint Bone Spine 82: 258-263, 2015. 
133. Lauber K, Keppeler H, Munoz LE, Koppe U, Schröder K, Yamaguchi H, Krönke G, Uderhardt S, Wesselborg S, Belka C, et al: Milk fat globule-EGF factor 8 mediates the enhancement of apoptotic cell clearance by glucocorticoids. Cell Death Differ 20: 1230-1240, 2013.

134. Zagórska A, Través PG, Lew ED, Dransfield I and Lemke G: Diversification of TAM receptor tyrosine kinase function. Nat Immunol 15: 920-928, 2014.

135. Elliott MR and Ravichandran KS: Clearance of apoptotic cells: Implications in health and disease. J Cell Biol 189: 1059-1070, 2010.

136. Maderna P, Yona S, Perretti M and Godson C: Modulation of phagocytosis of apoptotic neutrophils by supernatant from dexamethasone-treated macrophages and annexin-derived peptide Ac(2-26). J Immunol 174: 3727-3733, 2005.

137. Majai G, Sarang Z, Csomós K, Zahuczky G and Fésüs L: PPARgamma-dependent regulation of human macrophages in phagocytosis of apoptotic cells. Eur J Immunol 37: 1343-1354, 2007.

138. Kawano $M$ and Nagata S: Efferocytosis and autoimmune disease. Int Immunol 30: 551-558, 2018.

139. Tait AS, Butts CL and Sternberg EM: The role of glucocorticoids and progestins in inflammatory, autoimmune and infectious disease. J Leukoc Biol 84: 924-931, 2008.

140. Wolf SA, Boddeke HW and Kettenmann H: Microglia in physiology and disease. Annu Rev Physiol 79: 619-643, 2017.

141. Radi E, Formichi P, Battisti C and Federico A: Apoptosis and oxidative stress in neurodegenerative diseases. J Alzheimers Dis 42 (Suppl 3): S125-S152, 2014

142. Fuller AD and Eldik LJ: MFG-E8 regulates microglial phagocytosis of apoptotic neurons. J Neuroimmune Pharmacol 3 : 246-256, 2008

143. Ji R, Tian S, Lu HJ, Lu Q, Zheng Y, Wang X, Ding J, Li Q and Lu Q: TAM receptors affect adult brain neurogenesis by negative regulation of microglial cell activation. J Immunol 191: 6165-6177, 2013.

144. Ramachandran G and Udgaonkar JB: Mechanistic studies unravel the complexity inherent in tau aggregation leading to Alzheimer's disease and the tauopathies. Biochemistry 52: 4107-4126, 2013.

145. Zheng Y, Wang Q, Xiao B, Lu Q, Wang Y and Wang X: Involvement of receptor tyrosine kinase Tyro3 in amyloidogenic APP processing and $\beta$-amyloid deposition in Alzheimer's disease models. PLoS One 7: e39035, 2012.

146. Fricker M, Neher JJ, Zhao JW, Théry C, Tolkovsky AM and Brown GC: MFG-E8 mediates primary phagocytosis of viable neurons during neuroinflammation. J Neurosci 32: 2657-2666, 2012

147. Xu X, Zhang A, Zhu Y,He W, Di W, Fang Y and Shi X: MFG-E8 reverses microglial-induced neurotoxic astrocyte (A1) via NF- $\kappa \mathrm{B}$ and PI3K-Akt pathways. J Cell Physiol 234: 904-914, 2018

148. Shi X, Cai X, Di W, Li J, Xu X, Zhang A, Qi W, Zhou Z and Fang Y: MFG-E8 selectively inhibited A $\beta$-induced microglial M1 polarization via NF- $\mathrm{KB}$ and PI3K-Akt pathways. Mol Neurobiol 54: 7777-7788, 2017.

149. Xu X, Cai X, Zhu Y, He W, Wu Q, Shi X, Fang Y and Pei Z: MFG-E8 inhibits A $\beta$-induced microglial production of cathelicidin-related antimicrobial peptide: A suitable target against Alzheimer's disease. Cell Immunol 331: 59-66, 2018.

150. Kalia LV, Kalia SK, McLean PJ, Lozano AM and Lang AE: $\alpha$-Synuclein oligomers and clinical implications for Parkinson disease. Ann Neurol 73: 155-169, 2013.

151. Gardai SJ, Mao W, Schüle B, Babcock M, Schoebel S Lorenzana C, Alexander J, Kim S, Glick H, Hilton K, et al: Elevated alpha-synuclein impairs innate immune cell function and provides a potential peripheral biomarker for Parkinson's disease. PLoS One 8: e71634, 2013

152. Cardona AE, Pioro EP, Sasse ME, Kostenko V, Cardona SM Dijkstra IM, Huang D, Kidd G, Dombrowski S, Dutta R, et al Control of microglial neurotoxicity by the fractalkine receptor. Nat Neurosci 9: 917-924, 2006.

153. Depboylu C, Schäfer MK, Arias-Carrión O, Oertel WH, Weihe E and Höglinger GU: Possible involvement of complement factor $\mathrm{Clq}$ in the clearance of extracellular neuromelanin from the substantia nigra in Parkinson disease. J Neuropatho Exp Neurol 70: 125-132, 2011

154. Michelakakis H, Xiromerisiou G, Dardiotis E, Bozi M, Vassilatis D, Kountra PM, Patramani G, Moraitou M, Papadimitriou D, Stamboulis E, et al: Evidence of an association between the scavenger receptor class B member 2 gene and Parkinson's disease. Mov Disord 27: 400-405, 2012.
155. Cahoy JD, Emery B, Kaushal A, Foo LC, Zamanian JL, Christopherson KS, Xing Y, Lubischer JL, Krieg PA, Krupenko SA, et al: A transcriptome database for astrocytes, neurons and oligodendrocytes: A new resource for understanding brain development and function. J Neurosci 28: 264-278, 2008

156. Fourgeaud L, Través PG, Tufail Y, Leal-Bailey H, Lew ED, Burrola PG, Callaway P, Zagórska A, Rothlin CV, Nimmerjahn A and Lemke G: TAM receptors regulate multiple features of microglial physiology. Nature 532: 240-244, 2016.

157. Nakashima Y, Miyagi-Shiohira C, Noguchi H and Omasa T: The healing effect of human milk fat Globule-EGF factor 8 protein (MFG-E8) in A rat model of Parkinson's disease. Brain Sci 8: 167, 2018

158. Ghahremani Piraghaj M, Soudi S, Ghanbarian H, Bolandi Z, Namaki S and Hashemi SM: Effect of efferocytosis of apoptotic mesenchymal stem cells (MSCs) on C57BL/6 peritoneal macrophages function. Life Sci 212: 203-212, 2018.

159. Werfel TA and Cook RS: Efferocytosis in the tumor microenvironment. Semin Immunopathol 40: 545-554, 2018.

160. Jetten N, Verbruggen S, Gijbels MJ, Post MJ, De Winther MP and Donners MM: Anti-inflammatory M2, but not pro-inflammatory M1 macrophages promote angiogenesis in vivo. Angiogenesis 17: 109-118, 2014.

161. Han Q, Shi H and Liu F: CD163(+) M2-type tumor-associated macrophage support the suppression of tumor-infiltrating T cells in osteosarcoma. Int Immunopharmacol 34: 101-106, 2016.

162. Finkernagel F, Reinartz S, Lieber S, Adhikary T, Wortmann A, Hoffmann N, Bieringer T, Nist A, Stiewe T, Jansen JM, et al: The transcriptional signature of human ovarian carcinoma macrophages is associated with extracellular matrix reorganization. Oncotarget 7: 75339-75352, 2016.

163. Yeh HW, Chiang CF, Chen PH, Su CC, Wu YC, Chou L, Huang RY, Liu SY and Shieh YS: Axl involved in mineral trioxide aggregate induces macrophage polarization. J Endod 44: $1542-1548,2018$

164. Graham DK, Salzberg DB, Kurtzberg J, Sather S, Matsushima GK, Keating AK, Liang X, Lovell MA, Williams SA, Dawson TL, et al: Ectopic expression of the proto-oncogene Mer in pediatric T-cell acute lymphoblastic leukemia. Clin Cancer Res 12: 2662-2669, 2006.

165. Wang Y, Moncayo G, Morin P Jr, Xue G, Grzmil M, Lino MM, Clément-Schatlo V, Frank S, Merlo A and Hemmings BA: Mer receptor tyrosine kinase promotes invasion and survival in glioblastoma multiforme. Oncogene 32: 872-882, 2013

166. Schlegel J, Sambade MJ, Sather S, Moschos SJ, Tan AC, Winges A, DeRyckere D, Carson CC, Trembath DG, Tentler JJ, et al: MERTK receptor tyrosine kinase is a therapeutic target in melanoma. J Clin Invest 123: 2257-2267, 2013.

167. Myers KV, Amend SR and Pienta KJ: Targeting Tyro3, Axl and MerTK (TAM receptors): Implications for macrophages in the tumor microenvironment. Mol Cancer 18: 94, 2019.

168. Bondanza A, Zimmermann VS, Rovere-Querini P, Turnay J, Dumitriu IE, Stach CM, Voll RE, Gaipl US, Bertling W, Pöschl E, et al: Inhibition of phosphatidylserine recognition heightens the immunogenicity of irradiated lymphoma cells in vivo. J Exp Med 200: 1157-1165, 2004.

169. Linger RM, Keating AK, Earp HS and Graham DK: Taking aim at Mer and Axl receptor tyrosine kinases as novel therapeutic targets in solid tumors. Expert Opin Ther Targets 14: 1073-1090, 2010.

170. Sawabu T, Seno H, Kawashima T, Fukuda A, Uenoyama Y, Kawada M, Kanda N, Sekikawa A, Fukui H, Yanagita M, et al: Growth arrest-specific gene 6 and Axl signaling enhances gastric cancer cell survival via Akt pathway. Mol Carcinog 46: 155-164, 2007.

171. Lee-Sherick AB, Eisenman KM, Sather S, McGranahan A, Armistead PM, McGary CS, Hunsucker SA, Schlegel J, Martinson H, Cannon C, et al: Aberrant Mer receptor tyrosine kinase expression contributes to leukemogenesis in acute myeloid leukemia. Oncogene 32: 5359-5368, 2013

172. Brightwell RM, Grzankowski KS, Lele S, Eng K, Arshad M, Chen $\mathrm{H}$ and Odunsi K: The CD47 'don't eat me signal' is highly expressed in human ovarian cancer. Gynecol Oncol 143: 393-397, 2016

173. Willingham SB, Volkmer JP, Gentles AJ, Sahoo D, Dalerba P, Mitra SS, Wang J, Contreras-Trujillo H, Martin R, Cohen JD, et al: The CD47-signal regulatory protein alpha (SIRPa) interaction is a therapeutic target for human solid tumors. Proc Natl Acad Sci USA 109: 6662-6667, 2012. 
174. Chao MP, Alizadeh AA, Tang C, Myklebust JH, Varghese B, Gill S, Jan M, Cha AC, Chan CK, Tan BT, et al: Anti-CD47 antibody synergizes with rituximab to promote phagocytosis and eradicate non-Hodgkin lymphoma. Cell 142: 699-713, 2010.

175. Liang YY, Schwarzinger I, Simonitsch-Klupp I, Agis H and Oehler R: Impaired efferocytosis by monocytes in multiple myeloma. Oncol Lett 16: 409-416, 2018.

176. Terzić J, Grivennikov S, Karin E and Karin M: Inflammation and colon cancer. Gastroenterology 138: 2101-2114.e5, 2010.

177. Lew DS, Mazzoni F and Finnemann SC: Microglia inhibition delays retinal degeneration due to MerTK phagocytosis receptor deficiency. Front Immunol 11: 1463, 2020.

178. Jun JI, Kim KH and Lau LF: The matricellular protein CCN1 mediates neutrophil efferocytosis in cutaneous wound healing. Nat Commun 6: 7386, 2015.

179. Borucki DM, Toutonji A, Couch C, Mallah K, Rohrer B and Tomlinson S: Complement-mediated microglial phagocytosis and pathological changes in the development and degeneration of the visual system. Front Immunol 11: 566892, 2020.

180. Bossi F, Tripodo C, Rizzi L, Bulla R, Agostinis C, Guarnotta C, Munaut C, Baldassarre G, Papa G, Zorzet S, et al: C1q as a unique player in angiogenesis with therapeutic implication in wound healing. Proc Natl Acad Sci USA 111: 4209-4214, 2014.

181. Wang J, Wong YK and Liao F: What has traditional Chinese medicine delivered for modern medicine? Expert Rev Mol Med 20: e4, 2018

182. Wei J, Wang J, Ma G and Liu P: Effects of Guanxinkang on efferocytosis of spleen macrophages in LDLR-/-mice. Academic Journal of Shanghai University of Traditional Chinese Medicine 32: 56-61, 2018 (In Chinese).

183. Wang J, Mao M, Deng B and Liu P: Effects of Guanxinkang medicated serum on MerTK expression in RAW264.7 macrophages. Academic Journal of Shanghai University of Traditional Chinese Medicine 32: 45-48, 2018 (In Chinese).

184. Wang J and Liu P: Effects of Guanxinkang and its separate prescriptions on TAM receptor expression in peritoneal macrophages of $\mathrm{LDLR}^{-1-}$ atherosclerotic mice. Lishizhen Medicine and Materia Medica Research 29: 2326-2328, 2018 (In Chinese).

185. Susanti E, Ratnawati R, Aulani A and Rudijanto A: Catechins green tea upregulates the expression of ABCA1, ABCG1 and SRB1 in rats induced atherogenic diet. J Appl Pharma Sci 9 91-97, 2019

186. Li XY, Kong LX, Li J, He HX and Zhou YD: Kaempferol suppresses lipid accumulation in macrophages through the downregulation of cluster of differentiation 36 and the upregulation of scavenger receptor class B type I and ATP-binding cassette transporters A1 and G1. Int J Mol Med 31: 331-338, 2013.

187. Kim MS, Kim DS, Kim HS, Kang SW and Kang YH: Inhibitory effects of luteolin on transendothelial migration of monocytes and formation of lipid-laden macrophages. Nutrition 28 1044-1054, 2012.

188. Park SH, Kim JL, Lee ES, Han SY, Gong JH, Kang MK and Kang YH: Dietary ellagic acid attenuates oxidized LDL uptake and stimulates cholesterol efflux in murine macrophages. J Nutr 141: 1931-1937, 2011.

189. Guan S, Wang B, Li W, Guan J and Fang X: Effects of berberine on expression of LOX-1 and SR-BI in human macrophagederived foam cells induced by ox-LDL. Am J Chin Med 38 $1161-1169,2010$.

190. Uto-Kondo H, Ayaori M, Ogura M, Nakaya K, Ito M, Suzuki A, Takiguchi S, Yakushiji E, Terao Y, Ozasa H, et al Coffee consumption enhances high-density lipoprotein-mediated cholesterol efflux in macrophages. Circ Res 106: 779-787, 2010.

191. Ford HZ, Zeboudj L, Purvis GSD, Ten Bokum A, Zarebski AE, Bull JA, Byrne HM, Myerscough MR and Greaves DR Efferocytosis perpetuates substance accumulation inside macrophage populations. Proc Biol Sci 286: 20190730, 2019.

192. Dattaroy D, Seth RK, Das S, Alhasson F, Chandrashekaran V, Michelotti G, Fan D, Nagarkatti M, Nagarkatti P, Diehl AM and Chatterjee S: Sparstolonin B attenuates early liver inflammation in experimental NASH by modulating TLR4 trafficking in lipid rafts via NADPH oxidase activation. Am J Physiol Gastrointest Liver Physiol 310: G510-525, 2016.

193. Zhang X, Zhao Y, Zhang M, Pang X, Xu J, Kang C, Li M, Zhang C, Zhang Z, Zhang Y, et al: Structural changes of gut microbiota during berberine-mediated prevention of obesity and insulin resistance in high-fat diet-fed rats. PLoS One 7: e42529, 2012 .
194. Luo D, Guo Y, Cheng Y, Zhao J, Wang Y and Rong J: Natura product celastrol suppressed macrophage M1 polarization against inflammation in diet-induced obese mice via regulating Nrf2/HO-1, MAP kinase and NF- $\kappa$ B pathways. Aging (Albany NY) 9: 2069-2082, 2017.

195. Lai YS, Putra RBDS, Aui SP and Chang KT: M2 polarization by baicalin enhances efferocytosis via upregulation of MERTK receptor. Am J Chin Med 46: 1899-1914, 2018

196. Zhu W, Jin Z, Yu J, Liang J, Yang Q, Li F, Shi X, Zhu X and Zhang X: Baicalin ameliorates experimental inflammatory bowel disease through polarization of macrophages to an $\mathrm{M} 2$ phenotype. Int Immunopharmacol 35: 119-126, 2016.

197. Cai Q, Li Y and Pei G: Polysaccharides from Ganoderma lucidum attenuate microglia-mediated neuroinflammation and modulate microglial phagocytosis and behavioural response. J Neuroinflammation 14: 63, 2017.

198. Wu TF, Hsu CY, Huang HS, Chou SP and Wu H: Proteomic analysis of pycnogenol effects in RAW 264.7 macrophage reveals induction of cathepsin D expression and enhancement of phagocytosis. J Agric Food Chem 55: 9784-9791, 2007.

199. Tong H, Mao D, Zhai M, Zhang Z, Sun G and Jiang G: Macrophage activation induced by the polysaccharides isolated from the roots of Sanguisorba officinalis. Pharm Biol 53: $1511-1515,2015$

200. Wang H, Wei G, Liu F, Banerjee G, Joshi M, Bligh SW, Shi S Lian H, Fan H, Gu X and Wang S: Characterization of two homogalacturonan pectins with immunomodulatory activity from green tea. Int J Mol Sci 15: 9963-9978, 2014

201. Gheibi Hayat SM, Bianconi V, Pirro M and Sahebkar A: Efferocytosis: Molecular mechanisms and pathophysiological perspectives. Immunol Cell Biol 97: 124-133, 2019.

202. Holden RM, Hétu MF, Li TY, Ward EC, Couture LE, Herr JE Christilaw E, Adams MA and Johri AM: Circulating Gas6 is associated with reduced human carotid atherosclerotic plaque burden in high risk cardiac patients. Clin Biochem 64: 6-11, 2019.

203. Brophy ML, Dong Y, Tao H, Yancey PG, Song K, Zhang K, Wen A, Wu H, Lee Y, Malovichko MV, et al: Myeloid-specific deletion of epsins 1 and 2 reduces atherosclerosis by preventing LRP-1 downregulation. Circ Res 124: e6-e19, 2019.

204. Ait-Oufella H, Pouresmail V, Simon T, Blanc-Brude O, Kinugawa $\mathrm{K}$, Merval R, Offenstadt $\mathrm{G}$, Lesèche $\mathrm{G}$, Cohen PL, Tedgui A and Mallat Z: Defective mer receptor tyrosine kinase signaling in bone marrow cells promotes apoptotic cell accumulation and accelerates atherosclerosis. Arterioscler Thromb Vasc Biol 28: 1429-1431, 2008

205. Zhang Y, Wang Y, Zhou D, Zhang LS, Deng FX, Shu S, Wang LJ, Wu Y, Guo N, Zhou J and Yuan ZY: Angiotensin II deteriorates advanced atherosclerosis by promoting MerTK cleavage and impairing efferocytosis through the $\mathrm{AT}_{1} \mathrm{R} / \mathrm{ROS} / \mathrm{p} 38$ MAPK/ADAM17 pathway. Am J Physiol Cell Physiol 317: C776-C787, 2019.

206. Thorp E, Cui D, Schrijvers DM, Kuriakose G and Tabas I: Mertk receptor mutation reduces efferocytosis efficiency and promotes apoptotic cell accumulation and plaque necrosis in atherosclerotic lesions of apoe ${ }^{-/}$mice. Arterioscler Thromb Vasc Biol 28: 1421-1428, 2008.

207. Boisvert WA, Rose DM, Boullier A, Quehenberger O, Sydlaske A, Johnson KA, Curtiss LK and Terkeltaub R: Leukocyte transglutaminase 2 expression limits atherosclerotic lesion size. Arterioscler Thromb Vasc Biol 26: 563-569, 2006.

208. Gong S, Xu Z, Liu Y, Xing L, Ma J, Yu C, Liu X, Jia X, Xie R and Sui M: Plasma sMer, sAxl and GAS6 levels correlate with disease activity and severity in lupus nephritis. Eur J Clin Invest 49: e13064, 2019.

209. Tworkoski KA, Platt JT, Bacchiocchi A, Bosenberg M, Boggon TJ and Stern DF: MERTK controls melanoma cell migration and survival and differentially regulates cell behavior relative to AXL. Pigment Cell Melanoma Res 26 : 527-541, 2013.

210. Demarest SJ, Gardner J, Vendel MC, Ailor E, Szak S, Huang F, Doern A, Tan X, Yang W, Grueneberg DA, et al: Evaluation of Tyro3 expression, Gas6-mediated Akt phosphorylation and the impact of anti-Tyro3 antibodies in melanoma cell lines. Biochemistry 52: 3102-3118, 2013.

211. Xie S, Li Y, Li X, Wang L, Yang N, Wang Y and Wei H: Mer receptor tyrosine kinase is frequently overexpressed in human non-small cell lung cancer, confirming resistance to erlotinib. Oncotarget 6: 9206-9219, 2015. 
212. Walport MJ, Davies KA and Botto M: Clq and systemic lupus erythematosus. Immunobiology 199: 265-285, 1998.

213. Huang W, Wu J, Yang H, Xiong Y, Jiang R, Cui T and Ye D: Milk fat globule-EGF factor 8 suppresses the aberrant immune response of systemic lupus erythematosus-derived neutrophils and associated tissue damage. Cell Death Differ 24: 263-275, 2017.

214. Zhu H, Sun X, Zhu L, Hu F, Shi L, Li Z and Su Y: The expression and clinical significance of different forms of Mer receptor tyrosine kinase in systemic lupus erythematosus. J Immunol Res 2014: 431896, 2014.

215. Bertolaccini ML, Sanna G, Ralhan S, Gennari LC, Merrill JT, Khamashta MA and Hughes GR: Antibodies directed to protein $S$ in patients with systemic lupus erythematosus: Prevalence and clinical significance. Thromb Haemost 90: 636-641, 2003.
216. Peng Y and Elkon KB: Autoimmunity in MFG-E8-deficient mice is associated with altered trafficking and enhanced cross-presentation of apoptotic cell antigens. J Clin Invest 121: 2221-2241, 2011.

217. Avilla E, Guarino V, Visciano C, Liotti F, Svelto M, Krishnamoorthy G, Franco R and Melillo RM: Activation of TYRO3/AXL tyrosine kinase receptors in thyroid cancer. Cancer Res 71: 1792-1804, 2011

This work is licensed under a Creative Commons Attribution-NonCommercial-NoDerivatives 4.0 International (CC BY-NC-ND 4.0) License. 